\title{
Classical and alternative activation and metalloproteinase expression occurs in foam cell macrophages in male and female ApoE null mice in the absence of $T$ and B lymphocytes
}

\author{
Elaine Mo Hayes, Aikaterini Tsaousi, Karina Di Gregoli, S. Rhiannon Jenkinson, Andrew R. Bond, \\ Jason L. Johnson, Laura Bevan, Anita C. Thomas ${ }^{\dagger}$ and Andrew C. Newby ${ }^{* t}$
}

Bristol Heart Institute, School of Clinical Sciences, University of Bristol, Bristol, UK

\section{Edited by:}

Klaus Ley, La Jolla Institute for Allergy \& Immunology, USA

\section{Reviewed by:}

Carolyn Louise Geczy, University of New South Wales, Australia

Norbert Leitinger, University of

Virginia, USA

Almudena Ortega-Gomez,

Ludwig-Maximilians-Universität

München, Germany

${ }^{*}$ Correspondence:

Andrew C. Newby, Bristol Heart Institute, School of Clinical Sciences, University of Bristol, Bristol Royal Infirmary, Bristol BS2 8HW, UK

e-mail: a.newby@bristol.ac.uk

${ }^{\dagger}$ Anita C. Thomas and Andrew C. Newby have contributed equally to this work.
Background: Rupture of advanced atherosclerotic plaques accounts for most lifethreatening myocardial infarctions. Classical (M1) and alternative (M2) macrophage activation could promote atherosclerotic plaque progression and rupture by increasing production of proteases, including matrix metalloproteinases (MMPs). Lymphocyte-derived cytokines may be essential for generating M1 and M2 phenotypes in plaques, although this has not been rigorously tested until now.

Methods and results: We validated the expression of M1 markers (iNOS and COX-2) and M2 markers (arginase-1, Ym-1, and CD206) and then measured MMP mRNA levels in mouse macrophages during classical and alternative activation in vitro. We then compared mRNA expression of these genes ex vivo in foam cells from subcutaneous granulomas in fat-fed immune-competent ApoE knockout (KO) and immune-compromised ApoE/Rag-1 double-KO mice, which lack all T and B cells. Furthermore, we performed immunohistochemistry in subcutaneous granulomas and in aortic root and brachiocephalic artery atherosclerotic plaques to measure the extent of M1/M2 marker and MMP protein expression in vivo. Classical activation of mouse macrophages with bacterial lipopolysaccharide in vitro increased MMPs-13, -14, and -25 but decreased MMP-19 andTIMP-2 mRNA expressions. Alternative activation with IL-4 increased MMP-19 expression. Foam cells in subcutaneous granulomas expressed all M1/M2 markers and MMPs at ex vivo mRNA and in vivo protein levels, irrespective of Rag-1 genotype. There were also similar percentages of foam cell macrophages (FCMs) carrying M1/M2 markers and MMPs in atherosclerotic plaques from ApoE KO and ApoE/Rag-1 double-KO mice.

Conclusion: Classical and alternative activation leads to distinct MMP expression patterns in mouse macrophages in vitro. M1 and M2 polarization in vivo occurs in the absence of $\mathrm{T}$ and $\mathrm{B}$ lymphocytes in either granuloma or plaque FCMs.

Keywords: atherosclerosis, macrophages, lymphocytes, cytokines, plaque rupture

\section{INTRODUCTION}

Atherosclerotic plaque rupture underlies most myocardial infarctions and thromboembolic strokes, which are principal causes of mortality and morbidity worldwide (https://apps.who.int/ infobase/mortality.aspx). Macrophages play a key role in atherosclerosis progression, as demonstrated by their abundance in human plaques as foam cells and by the dramatic reduction in atherosclerosis in mice after genetic (1) or pharmacological (2) deletion of macrophages. Furthermore, production of mediators from activated macrophages is believed to be important in making plaques vulnerable to rupture (3). Reactive oxygen species, cytokines, and cell surface modifying proteinases produced by macrophages promote apoptosis, thereby contributing to the cellular rarefaction of vulnerable plaques (4). Moreover, extracellular proteinases, in particular matrix metalloproteinases (MMPs) can directly degrade the extracellular matrix and promote plaque instability (5). These proposed mechanisms are supported by the histological appearance of vulnerable plaques, which contain an abundance of macrophages expressing MMPs but a relative lack of smooth muscle cells (SMC) and extracellular matrix proteins, importantly collagens, which contribute tensile strength to the plaque cap (5). Intervening to diminish the production of these harmful mediators is therefore a rational approach to new therapies and this motivates efforts to understand the cellular and molecular mechanisms involved.

Early work highlighted the functional diversity of macrophages (6) and the existence of distinct phenotypes has become increasingly discussed (7). Polarization of macrophage into a so-called classically activated or M1 phenotype was recognized, possibly reflecting the context of infection where pathogen associated 
molecular patterns (PAMPs) and pro-inflammatory lymphocytederived cytokines, particularly interferons (IFNs) and interleukins (ILs) occurred in the same microenvironments. Consistent with this, the M1 phenotype is simulated in vitro by the combined action of PAMPs acting through Toll-like receptors (TLRs) and IFN $\gamma$ (8), with some evidence for synergy. Mechanisms underlying synergy include the ability of IFN $\gamma$ to prime responses to PAMPs by inducing expression of TLRs and their co-activators (9). Synergy also results from the combined activation of differing sig-

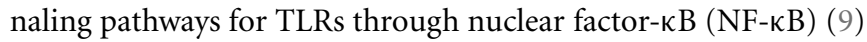
and IFN $\gamma$ through signal transducer and activator of transcription (STAT-1) (10).

The actions of IFN $\gamma$ have led to the hypothesis that Thelper1 (Th1)-lymphocytes may be essential for, or at least prominent contributors to, M1 polarization in vivo, a concept that has been acknowledged in papers dealing with atherosclerosis (11-13). It is consistent with studies showing that knockout (KO) of IFN $\gamma$ and its receptors reduces atherosclerosis progression (3), although the impact on M1 polarization was not measured directly in any of these IFN $\gamma \mathrm{KO}$ investigations. On the other hand, it is well recognized that other cytokines and combinations of cytokines that activate the pathways leading to $\mathrm{M} 1$ states could bypass the requirement for IFN $\gamma(9,14)$. Conversely, macrophages can polarized to a variety of alternatively activated or M2 states. The so-called M2a phenotype occurs after treatment with IL-4 or IL-13, which are potentially produced by Thelper2 (Th2) lymphocytes (15). Overall, this leads to the idea that T-lymphocytes, and, by implication, adaptive immunity play an essential part in M1/M2 macrophage polarization in atherosclerotic plaques. On the other hand, data from other areas of inflammation support the conclusion that M1/M2 polarization is primarily a function of innate immunity and that lymphocytes play a minor, at best modulatory role (16). Resolving this controversy is important for human atherosclerosis since a variety of immunotherapies have been proposed and some have already entered clinical trials (17).

Our present aim was formally to test the requirement for $\mathrm{T}$ and B lymphocytes in M1 and M2 macrophage activation and MMP production using an established ApoE-KO mouse model of atherosclerosis formation. To do this, we compared the expression of M1 and M2 markers, MMPs and the endogenous tissue inhibitors of MMPs (TIMPs) in foam cell macrophages (FCMs) from subcutaneous granulomas and atherosclerotic plaques in ApoE KO and ApoE/Rag-1 double-knockout (DKO) mice, which lack all $\mathrm{T}$ and B lymphocytes. As it is already known that there are differences in inflammation and plaque development between genders (18, 19), we used both male and female mice in this study. The mice were fed on a high-fat diet because it was previously shown that these conditions produced similar sized plaques in both genotypes (20). Hence, we could be sure that measurements of the prevalence of macrophages phenotypes would not be an artifact of different stages of atherosclerosis progression or plaque sizes.

\section{MATERIALS AND METHODS \\ BONE MARROW MONOCYTE ISOLATION AND DIFFERENTIATION TO BONE MARROW-DERIVED MACROPHAGES}

Mouse femurs and tibias were excised from C57BL/6 mice (Charles River, UK) on a normal diet. The bone ends were cut and bone marrow was flushed out with sterile phosphate-buffered saline (PBS). Erythrocytes were removed using ACK lysis buffer (Life Technologies, UK) and the pelleted white blood cells resuspended in PBS and counted, giving an average yield of $40 \times 10^{6}$ cells per mouse. Cells were plated into 24 -well plates at $0.5 \times 10^{6}$ cells/well and grown in RPMI 1640 media (Life Technologies) supplemented with antibiotics, glutamine, and $20 \%$ fetal calf serum (FCS) (Life Technologies) in the presence of $20 \mathrm{ng} / \mathrm{ml}$ recombinant human macrophage colony-stimulating factor (M-CSF, R\&D Systems, USA). The media was changed every 3-4 days. After 7-10 days, when the cells had differentiated into macrophages, M-CSF was removed and the cells exposed to selected cytokines for $18 \mathrm{~h}$ in serum-free media (SFM), as specified in the text. These included mouse (m) IFN $\gamma$ at $20 \mathrm{ng} / \mathrm{ml}$ (Miltenyi Biotec, USA), human (h) tissue necrosis factor (TNF)- $\alpha$ at $10 \mathrm{ng} / \mathrm{ml}$ (R\&D Systems, USA), mIL-4 at $10 \mathrm{ng} / \mathrm{ml}$ (PreproTech, UK), and lipopolysaccharide (LPS) at $10 \mathrm{ng} / \mathrm{ml}$ (Sigma-Aldrich, USA, L2654). Human cytokines were used only when their efficacy on mouse cells had been previously documented by the suppliers.

\section{PERIPHERAL BLOOD MONONUCLEAR CELL ISOLATION AND DIFFERENTIATION}

Pooled peripheral blood was collected by cardiac puncture from C57BL/6 mice with heparin as anti-coagulant. Monocytes were then isolated density gradient separation on Ficoll Paque Plus and differentiated to macrophages as previously described (21).

\section{RNA EXTRACTION, REVERSE TRANSCRIPTION, AND QUANTITATIVE PCR}

RNA lysates from cultured macrophages were collected using RLT solution (Qiagen Ltd, UK) with $\beta$-mercaptoethanol and the total RNA extracted using the Qiagen RNeasy kit (Qiagen Ltd), according to the manufacturer's instructions. The quantity and quality of resulting RNA was assessed using a NanoDrop ND-1000 spectrophotometer (LabTech International, UK). Samples of cDNA were generated using QuantiTect Reverse Transcription Kit (Qiagen Ltd), according to the manufacturer's instructions and the resulting cDNA was diluted 1:1 in $10 \mathrm{mM}$ TrisHCl, $\mathrm{pH}$ 8.0. Real time quantitative PCR was performed in a Roche Light Cycler 1.5 (Roche, UK) to quantify the steady-state concentration of RNA, using the QuantiTect SYBR Green PCR Kit (Qiagen Ltd). The primers used are listed in Table 1. Each reaction contained 2.5-7 ng RNA and $0.5 \mu \mathrm{M}$ primers. Initial denaturation $\left(15 \mathrm{~min}\right.$ at $\left.95^{\circ} \mathrm{C}\right)$ was followed by 55 cycles of denaturation $\left(15 \mathrm{~s}\right.$ at $\left.95^{\circ} \mathrm{C}\right)$, annealing $\left(20 \mathrm{~s}\right.$ at $\left.60^{\circ} \mathrm{C}\right)$, and extension $\left(25 \mathrm{~s}\right.$ at $\left.72^{\circ} \mathrm{C}\right)$. Copy numbers of gene transcripts per total nanogram RNA input were calculated using standard curves constructed as recommended by from purified amplicon (Bioline, USA).

\section{IN VIVO STUDIES}

Rag-1 KO mice that do not produce mature T or B cells (B6.129S7Rag- $1^{\text {tmlMom}} / \mathrm{J}$ ) and ApoE KO mice on a C57BL/6 background (B6.129P2-Apoe $e^{t m l U n c / J}$ ) were purchased from The Jackson Laboratories (USA), and bred together to create $\mathrm{ApoE}^{ \pm} / \mathrm{Rag}-1^{ \pm}$mice. Breeding stocks of ApoE KO and ApoE/Rag-1 DKO mice were obtained by crossing the resulting F1 generation. Mice were kept in scantainers and given sterile food and water ad libitum. All animal work was in accordance with the Home Office Guidance 
Table 1 | Primer sequences used for quantitative RT-PCR.

\begin{tabular}{|c|c|}
\hline Gene & Primer sequence \\
\hline \multirow[t]{2}{*}{ ARG-1 } & AGTCTGGCAGTTGGAAGCATCTCT \\
\hline & TTCCTTCAGGAGAAAGGACACAGG \\
\hline \multirow[t]{2}{*}{ COX-2 } & ATACTGGAAGCCGAGCACCTTTGG \\
\hline & ATGGTGGCTGTTTTGGTAGGCTGT \\
\hline \multirow[t]{2}{*}{ CD206 } & CCATTTATCATTCCCTCAGCAAGC \\
\hline & AAATGTCACTGGGGTTCCATCACT \\
\hline \multirow[t]{2}{*}{ FIZZ1 } & AGAGGTGGAGAACCCAGCTTTGAT \\
\hline & TTTCAAGAAGCAGGGTAAATGGGCA \\
\hline \multirow[t]{2}{*}{ IL-12p35 } & CCACAACAAGAGGGAGCTGCCTGCCC \\
\hline & AGTGCTGCGTTGATGGCCTGGAACT \\
\hline \multirow[t]{2}{*}{ IL-12p40 } & AGACCAGGCAGCTCGCAGCAAAGCA \\
\hline & GACACATCCCACTCCCACGCTGCC \\
\hline \multirow[t]{2}{*}{ iNOS } & CTCATGACATCGACCAGAAGCGT \\
\hline & TATATTGCTGTGGCTCCCATGTTG \\
\hline \multirow[t]{2}{*}{ MMP-2 } & GGCTGACATCATGATCAACTTTGG \\
\hline & GCCATCAGCCGTTCCCATACTTTAC \\
\hline \multirow[t]{2}{*}{ MMP-3 } & GCATCCCCTGATGTCCTCGTGG \\
\hline & TCCCCGGAGGGTGCTGACTG \\
\hline \multirow[t]{2}{*}{ MMP-8 } & TGCCTCGATGTGGAGTGCCTGA \\
\hline & GCCCTTGACAGCTGTGGCGT \\
\hline \multirow[t]{2}{*}{ MMP-9 } & AGAGAGGAGTCTGGGGTCTGGTTT \\
\hline & GAGAACACCACCGAGCTATCCACT \\
\hline \multirow[t]{2}{*}{ MMP-12 } & AATTACACTCCGGACATGAAGCGT \\
\hline & GGCTAGTGTACCACCTTTGCCATC \\
\hline \multirow[t]{2}{*}{ MMP-13 } & ATGATGATGAAACCTGGACAAGCA \\
\hline & ATAGGGCTGGGTCACACTTCTCTG \\
\hline \multirow[t]{2}{*}{ MMP-14 } & ACCACAAGGACTTTGCCTCTGAAG \\
\hline & CACCGAGCTGTGAGATTCCCTTGA \\
\hline \multirow[t]{2}{*}{ MMP-19 } & GATGAACTGGCCAGAACTGACCTT \\
\hline & GTCCCCGGTTGATGAGTTAGTGTC \\
\hline \multirow[t]{2}{*}{ MMP-23 } & CAAGGTTGGTGAGAGAGGGTAGGA \\
\hline & AGGAGTAGGTGCTGAGAACACGCT \\
\hline \multirow[t]{2}{*}{ MMP-25 } & CTCTGAGTGGCAGTGTTTGGAAGA \\
\hline & TGATGTCAGGCTCCTGGTACTGAG \\
\hline \multirow[t]{2}{*}{ TIMP-1 } & AGGAACGAAATTTGCACATCAGT \\
\hline & CAAAGTGACGGCTCTGGTAGTCCT \\
\hline \multirow[t]{2}{*}{ TIMP-2 } & GACTCССССТCAGАСТСТСССТАC \\
\hline & CATATTGATACCACCGCACAGGAA \\
\hline \multirow[t]{2}{*}{ TIMP-3 } & CACATCAAGGTGCCATTCAGGTAG \\
\hline & GTTCTСТССТССТСААСССАААСА \\
\hline \multirow[t]{2}{*}{ Ym1 } & CAGGTCTGGCAATTCTTCTG \\
\hline & GTCTTGCTCATGTGTGTAAGTG \\
\hline
\end{tabular}

on the operation of the Animals (Scientific Procedures) Act 1986 and conforms to the Guide for the Care and Use of Laboratory Animals published by the US National Institutes of Health (NIH Publication No. 85-23, revised 1996). Genotyping of the mice was performed on ear or tail pieces, using the Direct PCR kit (Bioquote, UK or Viagen Biotech, USA) after a Proteinase K digestion (Sigma, UK). PCR was performed using Crimson Taq Pol (New England Biolabs, UK), with dNTPs from Bioline (UK), using primers designed by The Jackson Laboratories. Male and female mice commenced a sterile high-fat diet (21-23\% fat, Special Diet Services, UK) at 5 weeks of age, and were sacrificed with an anesthetic overdose 12 weeks later. Blood was taken via cardiac puncture and heparinized plasma was subsequently analyzed for total, HDL, and LDL/VLDL cholesterol (Cholesterol/Cholesterol Ester Quantification Kit, Abcam, UK), after a minor adaptation of the manufacturer's instructions. The levels of selected M1 and M2 cytokines was assessed in additional samples of mouse plasma using a Bio-Plex Pro Mouse Cytokine Th1/Th2 Panel 8-plex (BioRad, USA). After the cardiac puncture, fresh tissue samples were taken (tail tip, spleen, liver lobe) and the animals perfused via the heart with PBS, then $10 \%$ formalin, at a constant pressure of $100 \mathrm{mmHg}$, with outflow through the left jugular vein. The brachiocephalic artery (BCA) (with a small piece of aortic arch), heart and remaining ascending and descending aorta were cleaned and removed from each mouse. Other tissues harvested included thymus and remaining liver. Tissue blocks of spleen less than $0.5 \mathrm{~cm}$ thick were post-fixed in $10 \%$ formalin for $24 \mathrm{~h}$ for subsequent histological examination, as described below.

\section{SPONGE IMPLANTATION AND FOAM CELL MACROPHAGE ISOLATION}

ApoE KO or DKO mice were fed the same high-fat diet as above from 6 weeks of age. Two weeks later these mice had $0.5 \mathrm{~cm}^{3}$ sterile polyurethane sponges containing $\sim 50 \mu \mathrm{l}$ of Matrigel (VWR, UK) placed under the dorsal skin under halothane anesthesia to generate FCMs as described previously $(22,23)$. The mice were fed the high-fat diet for a further 4 weeks. Recovered sponges were either fixed and embedded for immunohistological examinations as described below or the FCM were isolated and studied ex vivo. Fresh sponges were treated with $0.75 \mathrm{ml}$ undiluted Dispase (VWR, UK or BD Biosciences, USA) and then squeezed to obtain a cellular exudate. FCM were then purified, as previously described $(22,24)$ by flotation after centrifugation on a metrizamide gradient $(1.3507$ refractive index, Sigma) followed by differential adherence. Only foam cells (validated by Oil-red-O staining) float because of the relatively low buoyant density of lipid.

Samples were taken from each preparation immediately for protein or RNA isolation, and mRNA levels quantified as described above. Other cell preparations were cultured for a short period, to allow adherence to coverslips. Oil-Red-O (2\% Oil-red-O in isopropanol; Sigma) staining was performed to confirm lipid content, and immunocytochemistry performed to confirm cell purity. Cells were also assessed for their proliferative capacity [BrdU (Sigma) incorporation, $8 \mathrm{~h}$ pulse] or in situ zymography (25). In this assay, the gelatinolytic capacity of the macrophages isolated from the sponges was determined using the EnzChek gelatinase/collagenase assay kit (Invitrogen, USA). Controls included cells treated with EDTA, 1,10-phrenanthroline (Sigma) or GM6001 (Millipore, UK), to prevent MMP activity. Cells were fixed in paraformaldehyde and mounted in Vectorshield + DAPI (Vector Labs, USA). Several fields were photographed on each coverslip and the proportion of cells with gelatinase activity as indicated by the loss of fluorescence of the DQ-gelatin substrate determined.

\section{HISTOLOGICAL METHODS}

The proximal aorta and BCA from each mouse were embedded in paraffin and $3 \mu \mathrm{m}$ sections cut at $3 \mu \mathrm{m}$ intervals from the 
atherosclerosis-prone areas of these vascular beds, as described previously $(23,26)$. The first section after the bifurcation of the BCA from the aorta was cleared and rehydrated and then stained using Miller's elastin/van Gieson (EVG) and plaque dimensions were measured using image analysis software (Image Pro, DataCell, Maidenhead, UK), as described previously (23). The aortic sinus from each mouse was treated and examined in a similar fashion, with the first leaflet section (from the aorta) stained using EVG, with subsequent image analysis being performed (26). For immunohistochemistry, $3 \mu \mathrm{m}$ sections were brought to water and antigen retrieval performed using citrate buffer. Non-specific binding blocked with $10 \%$ goat serum (Sigma) in PBS. Primary antibodies for SMC ( $\alpha$-smooth muscle actin), macrophages [ Griffonia simplicifolia Lectin II (GSL)], iNOS, COX-2, CD206, arg-1, Ym-1, MMP-12, MMP-13, MMP-14, and TIMP-3 (see Table 2) were added to the sections and incubated either overnight at $4^{\circ} \mathrm{C}$ or for $1 \mathrm{~h}$ at room temperature. After washing and further incubations with goat anti-rabbit-biotin (Dako or Sigma) and ExtrAvidin-HRP (Sigma) staining was visualized using 3,3'diaminobenzidine (DAB, Sigma). A negative control where the primary antibody was replaced with the relevant species IgG at the same dilution was always included. The percentage of the

Table 2 | Primary and secondary antibodies and Griffonia simplicifolia Lectin II.

\begin{tabular}{|c|c|c|c|}
\hline & $\begin{array}{l}\text { Catalog } \\
\text { number }\end{array}$ & Type & Supplier \\
\hline \multicolumn{4}{|l|}{ Primary } \\
\hline GSL ॥ & B1215 & Lectin & Vector labs \\
\hline$\alpha$-Smooth muscle actin & M0851 & M_Mab & Dako \\
\hline arginase 1 & sc-20150 & Rb_PAb & Santa Cruz \\
\hline $\mathrm{BrdU}$ & B2531 & M_Mab & Sigma \\
\hline $\operatorname{cox} 2$ & ab15191 & Rb_PAb & Abcam \\
\hline iNOS & ab15323 & Rb_PAb & Abcam \\
\hline MOMA-2 & ab33451 & R_Mab & Abcam \\
\hline MMP-12 & ab52897 & $\mathrm{Rb} \_\mathrm{MAb}$ & Abcam \\
\hline MMP-13 & ab39012 & Rb_PAb & Abcam \\
\hline MMP-14 & ab51074 & Rb_MAb & Abcam \\
\hline STAT1p (phospho Y701) & ab30645 & Rb_PAb & Abcam \\
\hline STAT6p (phospho Tyr641) & 06-937 & Rb_PAb & Millipore \\
\hline TIMP-3 & Ab39206 & Rb_PAb & Abcam \\
\hline$Y m 1 / 2$ & 01404 & Rb_PAb & $\begin{array}{l}\text { Stemcell } \\
\text { Technologies }\end{array}$ \\
\hline rabbit IgG negative control & 15006 & & Sigma \\
\hline $\begin{array}{l}\text { mouse lgG2a negative } \\
\text { control }\end{array}$ & M5409 & & Sigma \\
\hline Goat serum & G9023 & & Sigma \\
\hline Rabbit serum & R9133 & & Sigma \\
\hline \multicolumn{4}{|l|}{ Secondary antibody } \\
\hline $\mathrm{Gt} \alpha \mathrm{M}$ & E0433 & Biotinylated & Dako \\
\hline GtaM & B6649 & Biotinylated & Sigma \\
\hline GtaRb & E0432 & Biotinylated & Dako \\
\hline GtaRb & B6649 & Biotinylated & Sigma \\
\hline $\mathrm{Rb} \alpha \mathrm{R}$ & E0468 & Biotinylated & Dako \\
\hline
\end{tabular}

plaque area stained with each cell-specific or phenotypic marker or MMP/TIMPs antibody was determined using the same image analysis software detailed above. The number of buried layers was assessed manually on sections stained with EVG and on sections using antibodies that recognize SMC. Paraffin-embedded sponge sections were treated similarly, and the presence of markers of macrophage activation examined. Oil-Red-O staining was performed en face, and the percentage of fatty deposits in each aorta was measured using NIH ImageJ v1.43.

\section{STATISTICAL METHODS}

All analyses were performed using GraphPad InStat v3.05 (GraphPad Software, Inc. USA) or SPSS v21 (IBM, USA) software. Data were checked for normality (Kolmogorov and Smirnov normality test), and logarithmic transformation of data performed if necessary. Regression analyses were performed using Pearson's correlation co-efficient. Statistical analyses of data were performed using Students $t$-test, a Mann-Whitney $U$-test or 1- or 2-way ANOVAs, with the 1-way ANOVA followed by a Bonferroni or Tukey-Kramer post-test. Data are expressed as arithmetic mean \pm SEM or geometric mean and $95 \%$ confidence limits, and statistical significance defined as $P<0.05$.

\section{RESULTS}

\section{IN VITRO STUDIES IN MOUSE BONE MARROW MACROPHAGES}

Bone marrow proved a convenient source of large quantities of mouse monocytes that were converted to bone marrow-derived macrophages (BMDM) using M-CSF. BMDM were 97\% F4/80 and CD11b double positive by flow cytometry (results not shown). We used mRNA expression for established M1 and M2 marker genes as positive controls for classic or alternatively activation. As expected from previous literature (15), classical activation with LPS alone or LPS plus IFN $\gamma$ increased mRNA levels of inducible NO synthase (iNOS, NOS-2) and cyclooxygenase-2 (COX-2) (Figure 1A), whereas alternative activation with IL-4 increased mRNA expression of arginase-I (arg-1), Ym-1, and CD206. We then investigated the concomitant regulation of a wide spectrum of MMPs and TIMPs, many of which have been previously implicated in atherosclerosis (27). The most abundant mRNAs under unstimulated conditions were MMP-12 > MMP-8 = MMP-19= MMP$14=$ TIMP-2 $>$ other MMPs and TIMPs (Figure 1B). Among the MMPs studied, MMP-13 showed the most dramatic 121-fold stimulation by LPS + IFN $\gamma$ (Figure 1B, note the scale is logarithmic). LPS + IFN $\gamma$ treatment also increased expressions of MMP-14 (11.3-fold) and MMP-25 (14.6-fold); and decreased expressions of MMP-19 (4.5-fold) and TIMP-2 (9.0-fold) (Figure 1B). Classical activation with a different mediator, tumor necrosis factor $\alpha$ $(\mathrm{TNF} \alpha)$, significantly increased expressions of MMP-2 (77-fold), MMP-9 (3.5-fold), and MMP-14 (3.5-fold) but not of MMP-13 (Figure 1B). Classical activation with $\mathrm{TNF} \alpha$ also increased MMP9 and MMP-14 expression in blood derived macrophages, similar to BMDM, but did not affect any of the other MMPs or TIMPs (results not shown). Treatment with IFN $\gamma$ did not increase mRNA levels of any MMP or TIMP in BMDM either alone or in the presence of LPS (Figures 1C,D). No effect of IFN $\gamma$ was observed in blood derived macrophages either (results not shown). Alternative activation with IL-4 increased mRNA expression of only MMP-19 


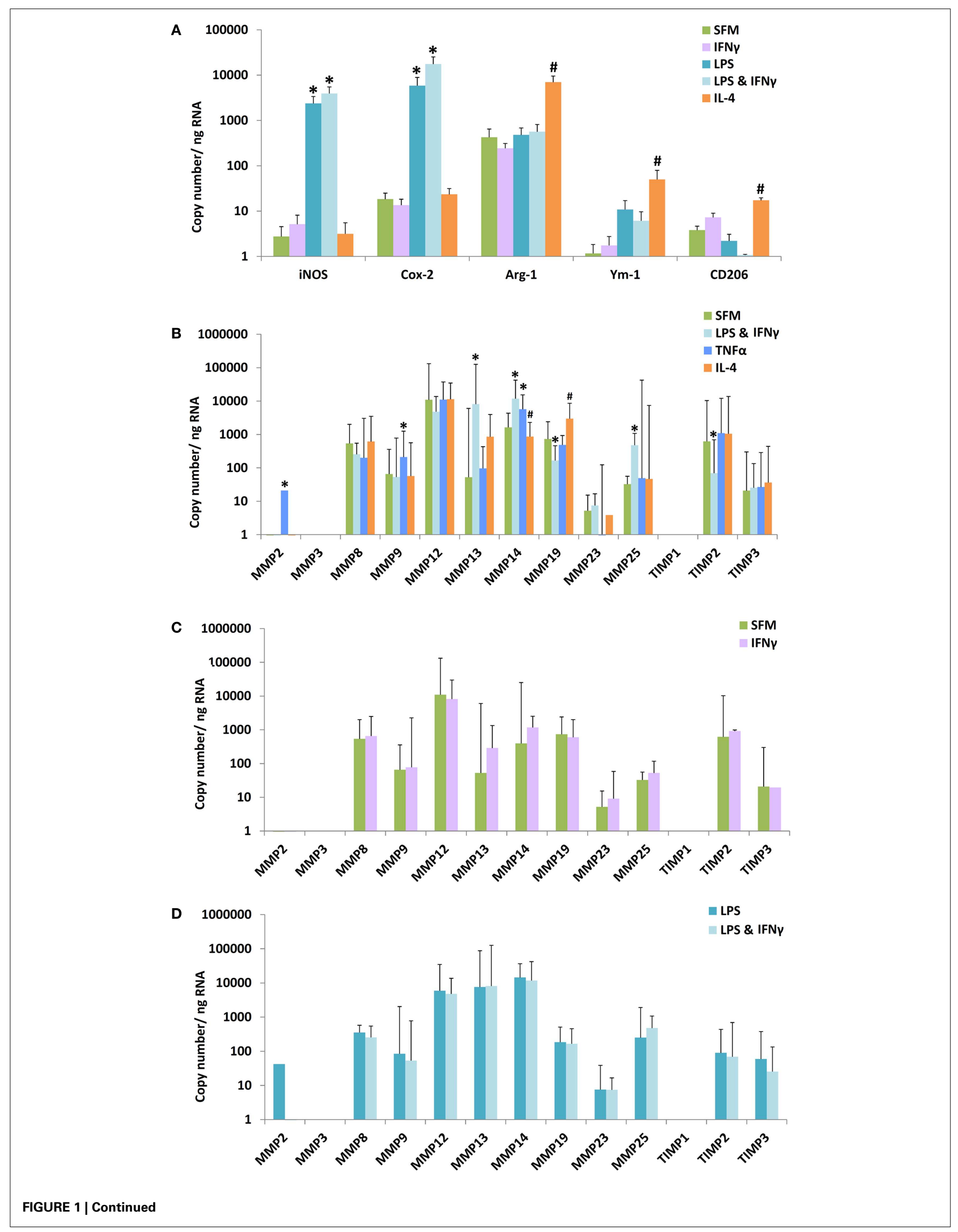




\section{FIGURE 1 | Continued}

Effect of M1/M2 polarization on mRNAs for markers, MMPs, and TIMPs in mouse bone marrow-derived macrophages. Monocytes from mouse bone marrow were differentiated to macrophages in M-CSF and then treated with bacterial lipopolysaccharide (LPS), interferon- $\gamma$ (IFN $\gamma$ ), tumor necrosis factor- $\alpha$ (TNF $\alpha$ ), or interleukin-4 (IL-4) alone or in combination, as indicated. SFM = serum-free medium. (A) The effect of polarization by IFN $\gamma$, LPS, LPS + IFN $\gamma$, or IL-4 on M1/M2 markers ( $n=4-5)$. (B) The effect of polarization by IFN $\gamma+L P S$, TNF $\alpha$, or IL-4 on MMPs and TIMPs ( $n=3-8)$. (C) Effect of IFN $\gamma$ alone on macrophages incubated in SFM. (D) Effect of IFN $\gamma$ on macrophages incubated in SFM containing LPS. Values are expressed as mean and SEM (A) or mean and 95\% confidence intervals (B-D). * $\mathrm{M} 1$ different from M0, ${ }^{*} \mathrm{M} 2$ different from $\mathrm{M} 0, P<0.05$.

Table 3 | Concentration of inflammatory and anti-inflammatory cytokines in plasma from ApoE KO or ApoE/Rag1 KO mice.

\begin{tabular}{|c|c|c|c|c|c|c|c|c|c|c|}
\hline & \multicolumn{2}{|c|}{ Male ApoE KO } & \multicolumn{2}{|c|}{ Male DKO } & \multirow[t]{2}{*}{$P$-value (males) } & \multicolumn{2}{|c|}{ Female ApoE KO } & \multicolumn{2}{|c|}{ Female DKO } & \multirow[t]{2}{*}{$\boldsymbol{P}$-value (females) } \\
\hline & Mean & SEM & Mean & SEM & & Mean & SEM & Mean & SEM & \\
\hline $\mathrm{IFN} \gamma$ & 11.88 & 4.353 & 5.680 & 2.902 & 0.2440 & 11.33 & 6.345 & 6.012 & 2.595 & 0.6275 \\
\hline $\mathrm{TNF} \alpha$ & $297.4^{a}$ & 56.00 & 206.3 & 23.16 & 0.1495 & 167.9 & 21.46 & 191.0 & 19.26 & 0.4331 \\
\hline GM-CSF & 118.0 & 24.55 & 106.4 & 16.66 & 0.6959 & 72.85 & 11.24 & 113.6 & 13.22 & 0.0304 \\
\hline IL-12p70 & 133.6 & 38.79 & 129.9 & 37.60 & 0.9457 & 58.65 & 12.61 & 127.7 & 29.90 & 0.0302 \\
\hline IL-10 & 15.23 & 3.023 & 23.99 & 3.852 & 0.0964 & 10.32 & 3.0 .03 & 25.38 & 2.486 & 0.0012 \\
\hline
\end{tabular}

Concentrations (picograms per milliliter) are expressed as mean and SEM, $n=9-10$. Bold type indicates $P<0.05$ for ApoE KO vs. DKO.

andicates significant gender difference for that genotype.

Table 4 | Concentration of cholesterol-containing lipoproteins in plasma from ApoE KO or ApoE/Rag1 KO mice.

\begin{tabular}{|c|c|c|c|c|c|c|c|c|c|c|}
\hline & \multicolumn{2}{|c|}{ Male ApoE KO } & \multicolumn{2}{|c|}{ Male DKO } & \multirow[t]{2}{*}{$P$-value (males) } & \multicolumn{2}{|c|}{ Female ApoE KO } & \multicolumn{2}{|c|}{ Female DKO } & \multirow[t]{2}{*}{$P$-value (females) } \\
\hline & Mean & SEM & Mean & SEM & & Mean & SEM & Mean & SEM & \\
\hline Total & $1360^{\mathrm{a}}$ & 116.5 & $1215^{a}$ & 47.04 & 0.3939 & 802.4 & 64.65 & 707.3 & 59.73 & 0.3050 \\
\hline $\mathrm{HDL}$ & 58.64 & 32.99 & 108.0 & 21.20 & 0.2364 & 14.39 & 3.177 & 85.86 & 41.76 & 0.0022 \\
\hline LDL + VLDL & $931.3^{a}$ & 71.77 & 508.4 & 99.79 & 0.0063 & 504.4 & 55.29 & 362.3 & 68.75 & 0.1384 \\
\hline
\end{tabular}

Concentrations (milligrams per deciliter) are expressed as mean and SEM, $n=6$. Bold type indicates $P<0.05$ for ApoE KO vs. DKO.

andicates significant gender difference for that genotype.

in BMDM (Figure 1B). These results revealed widely different levels of expression and divergent patterns of regulation of MMPs and TIMPs, which informed our choice of genes to measure in the subsequent in vivo experiments (see below).

\section{CIRCULATING INFLAMMATORY CYTOKINE AND CHOLESTEROL LEVELS IN ApoE KO AND ApoE/Rag-1 DOUBLE-KNOCKOUT MICE}

To investigate the impact of lymphocytes on M1/M2 polarization and MMP/TIMP expression, we compared ApoE $\mathrm{KO}$ and ApoE/Rag-1 DKO mice, which were genotyped using PCR to verify the deletion of ApoE alone or ApoE and Rag-1. The weight of the spleens of ApoE KO mice $(115 \pm 6 \mathrm{mg}, n=8)$ was reduced to $(56 \pm 9 \mathrm{mg}, n=10)$ in DKO mice and histological analysis of cut sections confirmed the absence of lymphocytes from DKO spleens (not shown). As expected, the expression of CD3 mRNA in the spleen, as a further marker of the presence of lymphocytes, was measurable in all ApoE $\mathrm{KO}$ mice tested (mean value $1.6 \pm 0.5$ copies/ng RNA, $n=10$ ) but undetectable in all DKO mice tested. We used blood levels of cytokines related to Th1 and Th2 lymphocytes to further characterize the inflammatory status of ApoE KO and DKO mice. As in Table 3, circulating levels of IFN $\gamma$ were low and not different between genotypes, whereas IL-4 levels were below the limits of detection of our assays. Of the more abundant cytokines, TNF $\alpha$ levels were not different, whereas GMCSF, IL-12, and IL-10 levels were elevated (1.6, 2.2, and 2.5-fold, respectively) in female $\mathrm{DKO}$ compared to ApoE $\mathrm{KO}$ mice. The same trend was seen for IL-10 levels in male mice (Table 3). These results showed, unexpectedly, that cytokines associated with M1 polarization (i.e., GM-CSF and IL-12) and M2 polarization (IL10) were at least the same or even elevated in DKO mice. We also noted that TNF- $\alpha$ levels were significantly 1.8 -fold higher in male than female ApoE KO mice but not different in DKO mice (Table 3).

Plasma cholesterol levels play a fundamental role in determining the extent of atherosclerosis in human beings and animal models. As shown in Table 4, the plasma concentrations of total cholesterol were not different between ApoE KO and DKO mice. HDL cholesterol was significantly increased sixfold in female DKO vs. ApoE KO mice and there was the same trend (1.9-fold) in the male mice. Conversely, LDL plus VLDL concentrations were significantly 1.8 -fold lower in male DKO than ApoE KO mice and same trend (1.4-fold) was seen for the females. We noted that total cholesterol levels were significantly higher in males than females of either genotype. Furthermore, VLDL + LDL levels 
were significantly higher in the male than female ApoE KO mice (Table 4). Based on increased HDL and decreased VLDL + LDL, $\mathrm{DKO}$ mice of either gender might be expected to be protected from atherosclerosis compared with ApoE KO mice.

\section{M1/M2 MARKER AND MMP mRNA LEVELS IN GRANULOMA FCMs FROM SUBCUTANEOUS SPONGES}

We sought a ready source of foam cells generated in vivo to investigate expression of the M1/M2 markers and MMPs and TIMPs measured in our in vitro study of non-foamy macrophages. Atherosclerotic plaques are small and difficult to disrupt but hypercholesterolemia promotes the accumulation of foam cells at several more accessible sites in human beings and mice. For example, foam cells accumulate in the peritoneum (28) or in granulomas that form in sterile sponges implanted subcutaneously into atherosclerosis-prone mice (23). In this study, FCMs were isolated from subcutaneous granulomas. They were purified based on their decreased buoyant density by flotation over a density gradient. The yield of foam cells from subcutaneous sponges implanted for 6 weeks into ApoE KO or DKO mice was $4.07 \pm 0.61 \times 10^{6}$ and $5.87 \pm 1.21 \times 10^{6}$ cells, respectively, and did not significantly vary between genders. Foam cells from ApoE KO mice were $95.5 \pm 1.6 \%$ macrophages (using MOMA-2 as a marker). FCMs had detectable levels of the same M1 and M2 markers seen in non-foamy BMDM, irrespective of whether they came from ApoE KO or DKO mice
(Table 5). We concluded that FCMs acquired M1 marker genes in the absence of $\mathrm{T}$ and $\mathrm{B}$ lymphocytes. Indeed, there was a trend toward higher levels of mRNA expression of M1 markers, iNOS and COX-2, in DKO animals, although this was not significant (Table 5). Given this somewhat surprising conclusion, we measured additional M1 markers, namely IL-12 p35 and p40 and SOCS3, which were also detectable and showed no significant difference between ApoE-KO and DKO mice (Table 5). The mRNAs for M2 markers arg-1, and Ym-1 were also expressed at similar levels in granuloma FCMs from ApoE KO or DKO mice (Table 5), whereas CD206 was slightly elevated in male DKO compared to ApoE KO mice. The data suggested that M2 polarization also occurred efficiently in the absence of lymphocytes. To confirm this, we added measurements of FIZZ1 and IL-10, which also showed no difference between ApoE KO and DKO FCMs (Table 5). We noted a few significant gender differences. The mRNA levels of the M1 marker, IL-12p40, and the M2 markers, CD206 and Ym-1, were approximately 50\% lower in granuloma FCMs from male compared to female ApoE KO mice.

The MMPs that were increased by classical activation in blood or BMDM, that is MMP-2, MMP-9, MMP-13, MMP-14, and MMP-25, were all expressed in granuloma FCMs, irrespective of Rag-1 genotype (Table 5). TIMP-2 (that was decreased by classical activation) and MMP-19 (that was decreased by classical activation and increased by alternative activation) were also expressed

Table 5 | Characteristics of foam cell macrophages obtained from subcutaneous sponges.

\begin{tabular}{|c|c|c|c|c|c|c|c|c|c|c|}
\hline & \multicolumn{2}{|c|}{ Male KO } & \multicolumn{2}{|c|}{ Male DKO } & \multirow[t]{2}{*}{$P$-value (males) } & \multicolumn{2}{|c|}{ Female ApoE } & \multicolumn{2}{|c|}{ Female DKO } & \multirow[t]{2}{*}{$P$-value (females) } \\
\hline & Mean & SEM & Mean & SEM & & Mean & SEM & Mean & SEM & \\
\hline $\operatorname{cox} 2$ & 915 & 135 & 2053 & 729 & 0.3692 & 931 & 134 & 1306 & 243 & 0.1981 \\
\hline iNOS & 56 & 7 & 474 & 305 & 0.3793 & 69 & 13 & 331 & 242 & 0.3357 \\
\hline IL-12p35 & 1085 & 88 & 904 & 130 & 0.2451 & 1563 & 299 & 1154 & 276 & 0.3316 \\
\hline IL-12p40 & $6^{a}$ & 1 & 9 & 3 & 0.7304 & 13 & 2 & 11 & 4 & 0.6432 \\
\hline sOCS3 & $1797^{a}$ & 204 & 4117 & 1060 & 0.1191 & 2679 & 327 & 3038 & 587 & 0.5896 \\
\hline Arg-1 & 79646 & 5095 & 87511 & 7825 & 0.3953 & 87172 & 14259 & 90946 & 10539 & 0.8345 \\
\hline CD206 & $1317^{a}$ & 198 & 2150 & 285 & 0.0224 & 2420 & 212 & 2293 & 372 & 0.7707 \\
\hline FIZZ1 & 377 & 58 & 518 & 82 & 0.1640 & 365 & 65 & 594 & 136 & 0.2810 \\
\hline IL-10 & 10262 & 1115 & $10234^{a}$ & 780 & 0.9852 & 12984 & 2289 & 19852 & 4366 & 0.1853 \\
\hline$Y m-1$ & $35^{a}$ & 5 & 78 & 31 & 0.3311 & 103 & 20 & 124 & 29 & 0.5530 \\
\hline MMP2 & 387 & 77 & 614 & 136 & 0.1462 & 535 & 97 & 681 & 173 & 0.4586 \\
\hline MMP9 & $104^{a}$ & 18 & 217 & 63 & 0.0720 & 182 & 22 & 155 & 14 & 0.3537 \\
\hline MMP12 & 176264 & 11743 & 150381 & 15260 & 0.1860 & 215896 & 28916 & 160661 & 26809 & 0.1831 \\
\hline MMP13 & 43800 & 3821 & 33103 & 3990 & 0.0664 & 48821 & 8573 & 34538 & 4202 & 0.1770 \\
\hline MMP14 & 4888 & 570 & 5402 & 462 & 0.4963 & 5214 & 917 & 5856 & 942 & 0.6332 \\
\hline MMP19 & 8486 & 1684 & 7893 & 930 & 0.7723 & 8756 & 998 & 7814 & 1268 & 0.5699 \\
\hline MMP25 & 23 & 3 & 112 & 47 & 0.6049 & 27 & 6 & 84 & 42 & 0.9307 \\
\hline TIMP-1 & $1674^{a}$ & 237 & 2321 & 399 & 0.1625 & 2543 & 330 & 1771 & 401 & 0.1571 \\
\hline TIMP-2 & $6624^{a}$ & 533 & 6984 & 730 & 0.6884 & 10456 & 682 & 6455 & 606 & 0.0008 \\
\hline TIMP-3 & $1203^{a}$ & 160 & 2728 & 689 & 0.0352 & 2228 & 356 & 2452 & 586 & 0.7434 \\
\hline
\end{tabular}

FCMs were isolated by density gradient centrifugation and differential adhesion from sponges implanted under the skin of ApoE KO or ApoE/Rag-1 DKO mice, as

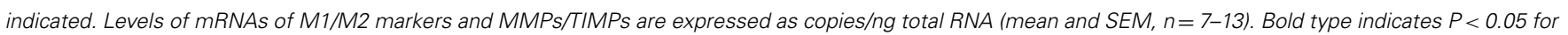
ApoE KO vs DKO.

${ }^{a}$ Indicates significant gender difference for that genotype. 
at high levels in both genotypes (Table 5). Female ApoE KO mice had 1.6-fold more TIMP-2 mRNA than the corresponding males. MMP-12 and TIMP-1 [that showed no relationship with classical/alternative phenotype under the conditions of our in vitro studies (Figure 1B)] were expressed irrespective of genotype, but TIMP-3 was significantly increased 2.3-fold in male DKO compared to ApoE KO mice. The proportion of granuloma FCMs able to degrade gelatin was determined using in situ zymography. A significantly higher percentage of granuloma FCMs had gelatinase activity from female DKO (91\%) compared with ApoE $\mathrm{KO}$ animals (76\%), and the same trend was evident in the in the males (86 vs. 74\%) (Figure 2A), Pooling the data, the $88 \%$ of the DKO mice had gelatinase activity compared to $75 \%$ in the ApoE KO mice $(P=0.0026)$. The proliferative capacity of FCMs was assessed by measuring BrdU incorporation (Figure 2B). Proliferation was not different in male mice of either genotype but was increased almost twofold in female ApoE $\mathrm{KO}$ mice compared to DKO mice $(P<0.0001)$. Migration through a matrigel layer in a modified Boyden chamber assay $(n=3-5)$ was not significantly different amongst granuloma FCMs from the two genotypes (results not shown).

\section{M1/M2 MARKER PROTEIN EXPRESSION AND PATHWAY ACTIVATION IN} GRANULOMA FCMS FROM SUBCUTANEOUS SPONGES

We used immunohistochemistry to confirm the protein expression of M1 and M2 markers in vivo by using sections taken from excised subcutaneous sponges. A subpopulation of granuloma cells in sponge sections stained for iNOS (Figures 3A,B) or COX-2 protein (Figures 3C,D) in either Rag-1 genotype. Control sections stained with isotype matched non-immune immunoglobulins had no staining (Figures 3E,F). Furthermore, a fraction of the granuloma cells in sponge sections stained for nuclear localized NF- $\mathrm{B}$ (Figures 4A,B) or phosphorylated STAT-1 (Figures 4C,D), indicating that these cells had undergone activation of the signaling pathways that are associated with M1 activation. Sections stained with isotype matched non-immune immunoglobulins had no staining (Figures 4E,F). Some FCMs in sections also stained for arg-1 (Figures 5A,B), Ym-1 (Figures 5C,D), or phosphorylated STAT-6 (Figures 5E,F), demonstrating the presence of marker proteins and active signaling pathways that are associated with M2 macrophages. Sections stained with isotype matched nonimmune immunoglobulins again had no staining (Figures 5G,H). Similar results to those with sponge sections were found by immunocytochemistry of FCM isolated from sponges (data not shown).

\section{PLAQUE SIZE, COMPOSITION, M1/M2 MARKERS, AND MMP PROTEIN EXPRESSION IN FCMS IN ATHEROSCLEROTIC PLAQUES FROM ApoE KO AND DKO MICE}

Plaques in the aortic sinus tended to be smaller in DKO compared with ApoE KO mice but this did not reach statistical significance (Figure 6A). However, in agreement with previous reports (18, 19), significant gender differences were observed (Figures 6A,B). Aortic sinus plaques were significantly bigger in females compared with males in ApoE KO (twofold: $P=0.0057$ ) and DKO (2.5-fold: $P=0.0043)$ mice. Plaques in the BCA were 2.1 times smaller in the DKO compared to ApoE KO males $(P=0.004)$ but there was no significant difference between the two genotypes in the females (Figure 6B). Interestingly, ApoE KO males had 2.9 times larger plaques when compared with ApoE KO females $(P<0.0001)$ (Figure 6B), which was the opposite of the relationship observed in the aortic sinus. This difference has also been noted before (29). These differences reinforced our decision to stratify our data by gender.

Buried fibrous layers in BCA plaques have been suggested as a marker of plaque complexity or instability (30). However, we observed no linear regression between the number of buried layers and plaque size ( $P$-values range from 0.20 to $0.68, n=15-17)$ or macrophage content ( $P$-values range from 0.29 to $0.99, n=15-17$ ), which are other measures that have been associated with plaque vulnerability. In any event, there were no significant differences in the number of buried layers in plaques from DKO compared to ApoE KO mice (Figure 6C). The area occupied by plaques in the aorta (as demonstrated by en face staining with Oil-Red-O) gives another measure of the extent of plaque progression in these mice. This did not change with phenotype or gender (Figure 6D).

The comparable plaque size in the aortic root of ApoE $\mathrm{KO}$ and DKO mice has been reported previously (20), and was consistent

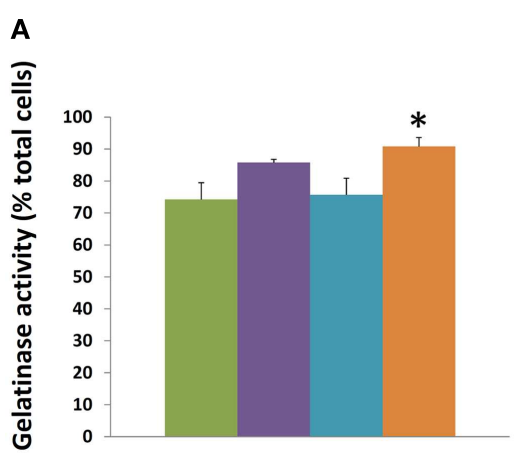

FIGURE 2 | Characteristics of foam cell macrophages (FCMs) obtained from subcutaneous granulomas. Granuloma FCMs were isolated by flotation over a density gradient and differential adhesion from sponges implanted under the skin of ApoE KO or ApoE/Rag-1 DKO mice, as

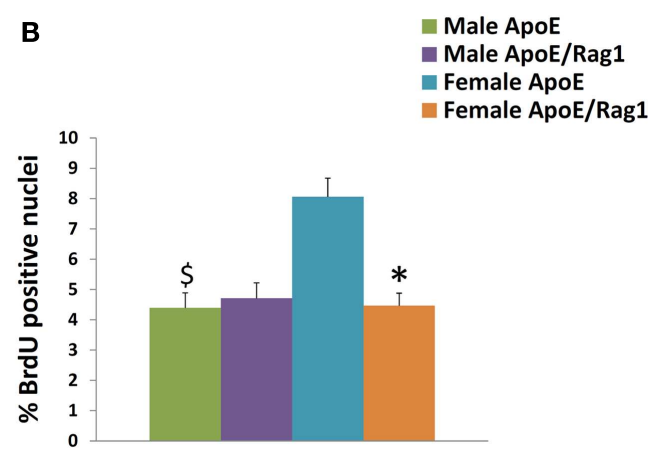

indicated. (A) In situ zymography (gelatinase activity, mean and SEM, $n=9-13)$. (B) Proliferative capacity ( $8 \mathrm{~h} \mathrm{BrdU}$ pulse, mean and SEM, $n=8-14) .{ }^{*} P<0.05$ vs. DKO, ${ }^{\$} P<0.05$ indicates gender differences for that genotype. 


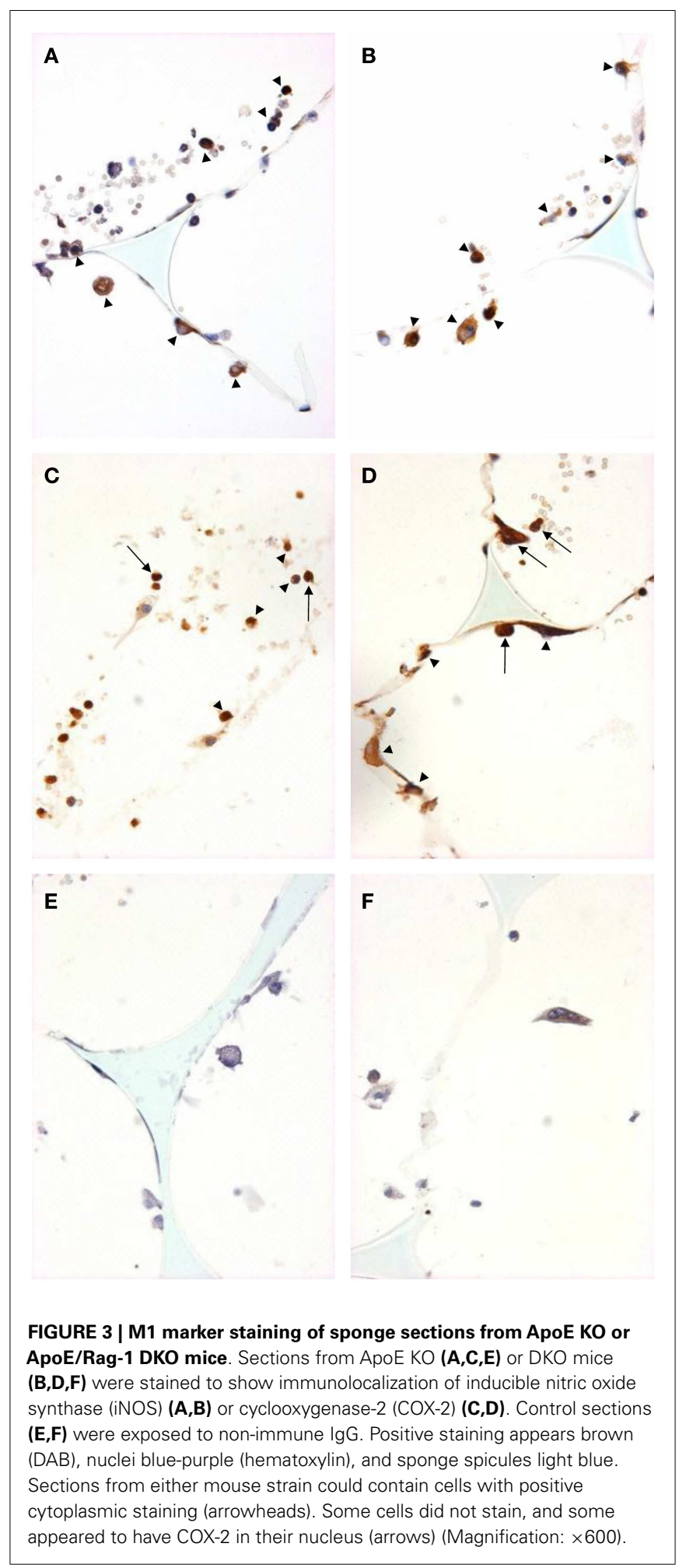

with the objective of our experimental design. It ensured that any difference in foam cell phenotype in the aortic sinus would be independent of plaque size. However, the larger plaque size in male BCA plaques in ApoE KO than DKO mice could complicate the interpretation of data relating to phenotypes in these mice.

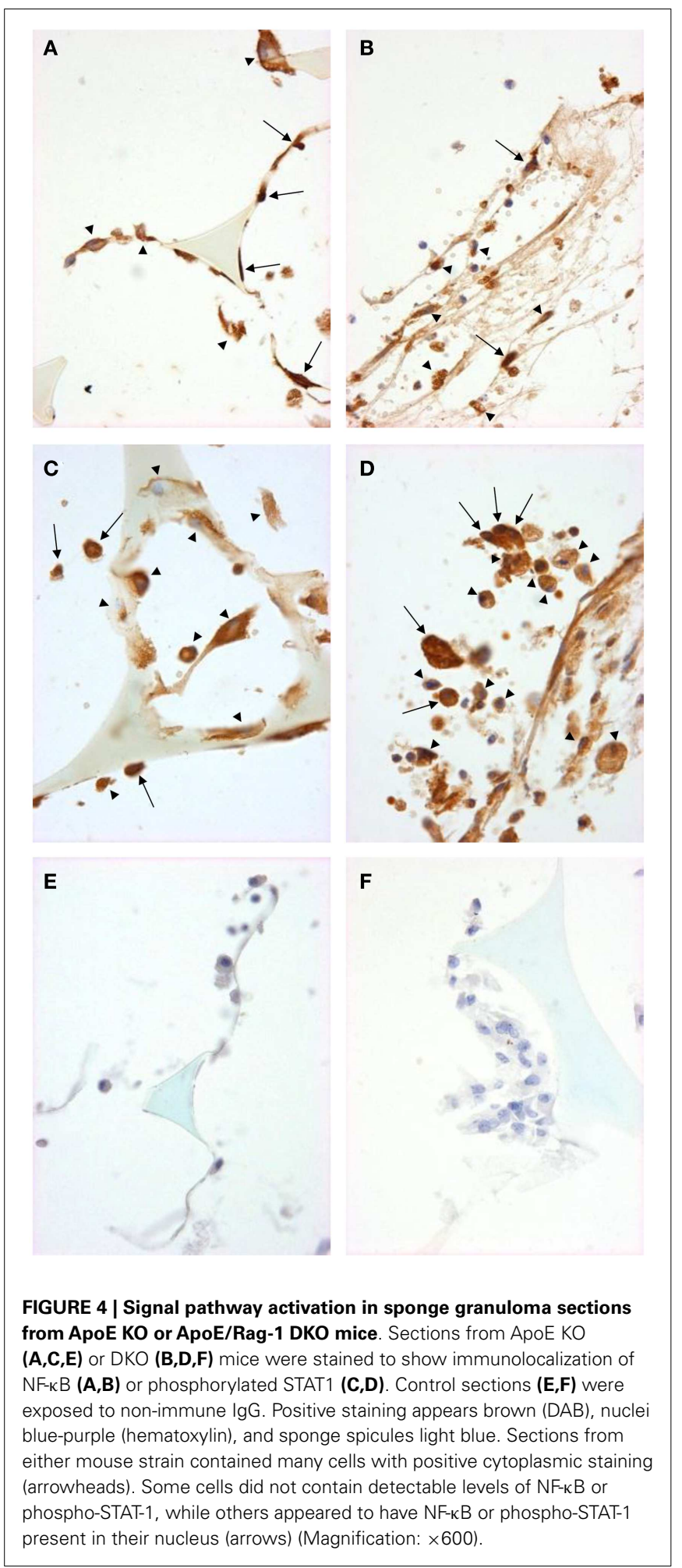

Immunohistochemistry for $\alpha$-smooth-muscle-cell-actin ( $\alpha$ SM-actin) was used to quantify the presence of vascular SMC and staining for GSL to quantify macrophages. As expected SMC were mainly found in the media and fibrous cap of plaques (Figures 7A-D). Most GSL positive had a foamy 


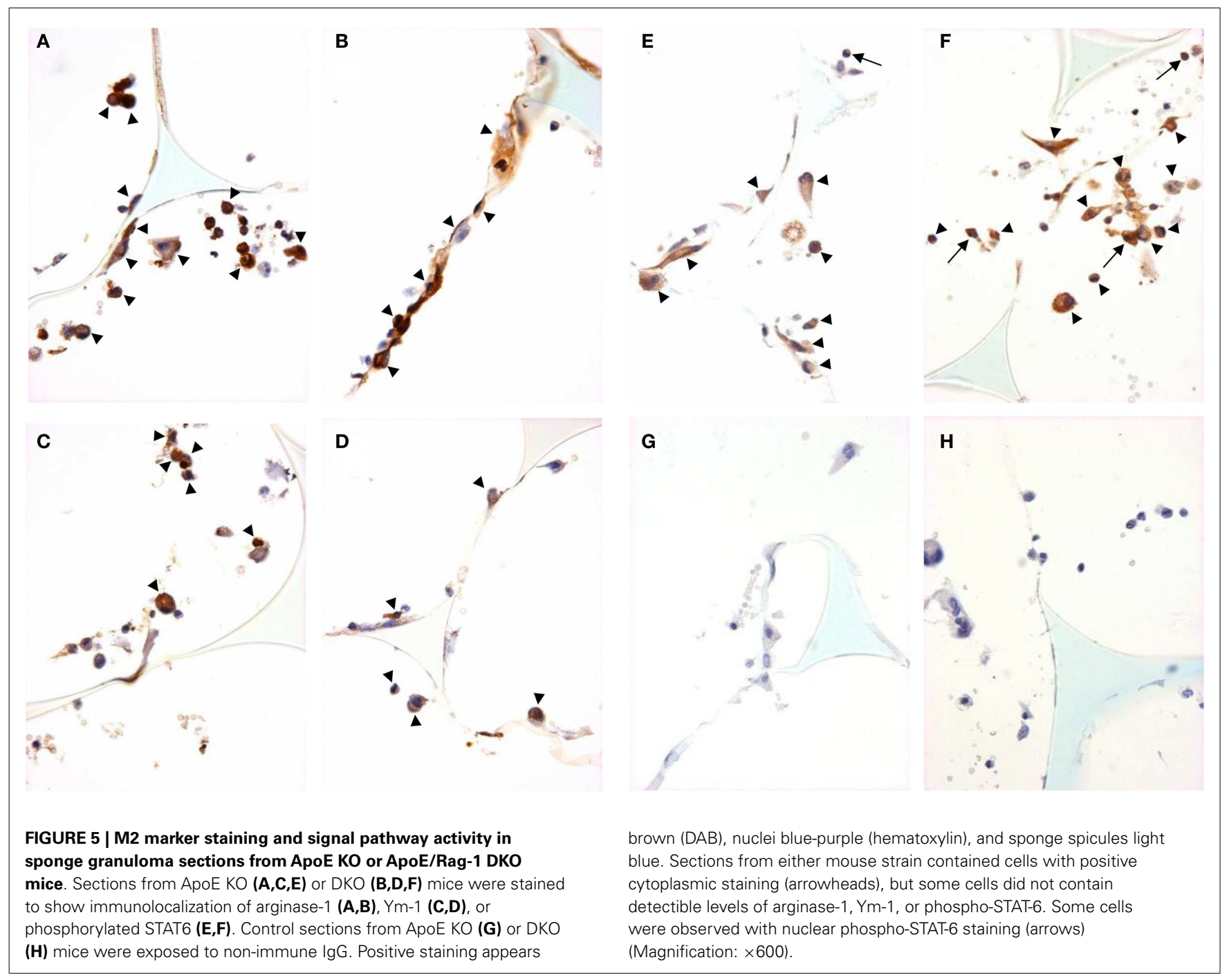

appearance on close examination and were therefore mainly FCMs (Figures 7A-D). However, some medial cells, presumably synthetic state SMC or SMC transdifferentiating toward macrophages (31) also stained with GSL (Figures 7A-D). Given the small size of atherosclerotic plaques in the AS and BCA, it was impractical to extract mRNA for qRT-PCR, or total protein for Western blotting. We therefore used immunohistological methods to quantify the presence of M1 and M2 markers as well as selected MMPs and TIMP-3. Our in vitro studies together with the availability of suitable antibodies (Table 2 ) guided our choice of iNOS as suitable M1 marker and arg-1 and Ym-1 as suitable M2 markers. Based again on our in vitro studies and the availability of suitable antibodies (Table 2), we chose to study MMP-13 and MMP-14 as potentially related to classical activation. MMP-12 and TIMP-3 were also chosen for comparison because they are abundantly expressed in vitro, irrespective of classical and alternative activation. For each of the antibodies and lectin used the staining was specific, both in the aortic sinus (Figures 7A,B) and the BCA (Figures 7C,D) of either genotype. Interestingly, phenotypic markers, MMPs and TIMP-3 were mainly associated with GSL-positive areas rather than $\alpha$ actin (Figures 7A-D). The percentage of the total plaque area stained with each antibody was measured using image analysis. By confining measurements to the plaque, we avoided any influence of staining from the media layer. Furthermore, some of the antibodies stained cardiac myocytes surrounding the aortic root (Figures 7A,B) but this did not distort our subsequent measurements because these areas were excluded from the quantification.

The area stained with $\alpha$-SM actin in the aortic sinus (Figure 8A) was less than $20 \%$ under all conditions, consistent with the lipidrich nature of plaques in this model at this time point. Nevertheless, SMC area was 1.5 times higher in the female DKO compared with ApoE KO mice $(P=0.0051)$ and the same trend was seen in the male mice. The pooled data for both genders were also significant $(P=0.0058)$ There were no differences between genotypes in the BCA (Figure 8B), although male DKO mice had 3.8-times more SMC staining than females (Figure 8B). Plaque areas stained with GSL were $30-40 \%$ in AS or BCA, consistent with highly inflamed nature of these plaques. GSL areas in the AS (Figure 8A) 

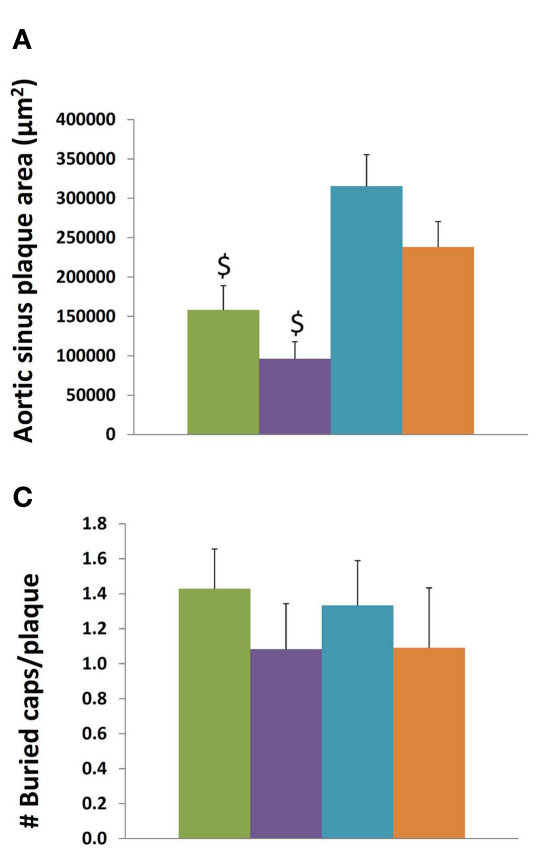

FIGURE 6 | Histological appearances of aortic sinus, brachiocephalic artery and aortic plaques in ApoE KO and ApoE/Rag-1 DKO mice. (A) Area of plaque in the aortic sinus. The first section showing leaflet of the aortic valve was stained using Miller's elastin/van Gieson (EVG) and the area of plaque in each section calculated using computer aided planimetry, $n=16-22$. (B) A section taken $3 \mu \mathrm{m}$ after the bifurcation of the brachiocephalic artery (BCA) from the aorta was treated and stained and
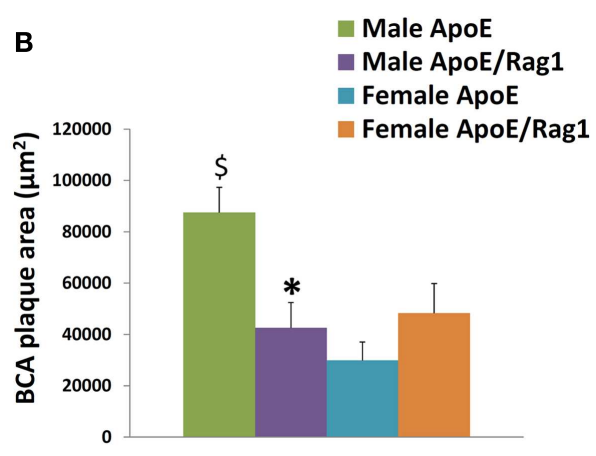

D

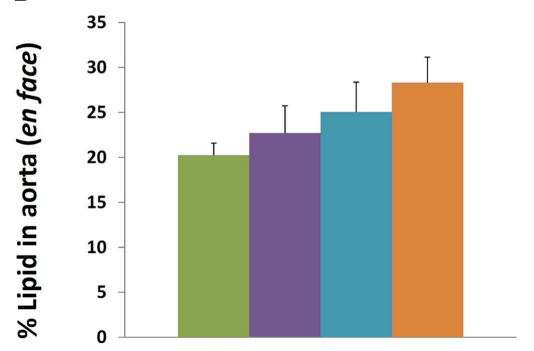

examined in a similar fashion to $A, n=13-19$. (C) The number of buried layers in plaque from BCA were assessed in EVG and $\alpha$-SM-actin stained sections, $n=11-14$. (D) Whole aorta were opened longitudinally and stained en face for the presence of neutral lipid using Oil-Red-O. The area of lipid-rich plaque in each aorta was calculated using computer aided planimetry, $n=10-11$. Values are expressed mean and SEM. ${ }^{*} P<0.05$ vs. DKO, ${ }^{\$} P<0.05$ indicates gender differences for that genotype.

Additional gender differences were also noted. Staining for iNOS in the aortic sinus was 2.4 times greater in the male than female mice of both ApoE KO and DKO mice (Figure 8A). Staining for arg-1 was 2.1 and 1.4-fold higher in male compared with female ApoE and DKO mice, respectively in the aortic sinus (Figure 8A) although not the BCA (Figure 8B). Staining for Ym-1 was similar between males and females of either genotype in the aortic sinus, and in ApoE KO in the BCA (Figures 8A,B).

The areas stained for MMPs-12, $-13,-14$, and TIMP- 3 were extensive in the aortic root and BCA plaques, which shows that these proteins are widely expressed in plaques (Figures $\mathbf{8 A}, \mathbf{B}$ ). The area of staining for MMP-13 and MMP-14 was similar in ApoE KO and DKO mice of either gender in the AS (Figure 8A) or BCA (Figure 8B). Clearly, the absence of $\mathrm{T}$ and $\mathrm{B}$ lymphocytes had little impact on extent of MMP-13 or MMP-14 staining, consistent with the PCR data obtained from granuloma FCMs. MMP-12, however, showed fourfold increased staining in male DKO compared to ApoE KO mice $(P=0.0261)$, although this was not replicated in the BCA (Figure $\mathbf{8 B}$ ) or in female mice. The areas of TIMP- 3 staining in the BCA were in all cases similar irrespective of genotype or gender (Figures 8A,B). Male mice of either genotype had approximately twice as much staining for MMP-13, MMP-14, or TIMP-3 than females in the AS (Figure 8A), although there was no difference in the BCA (Figure 8B). 

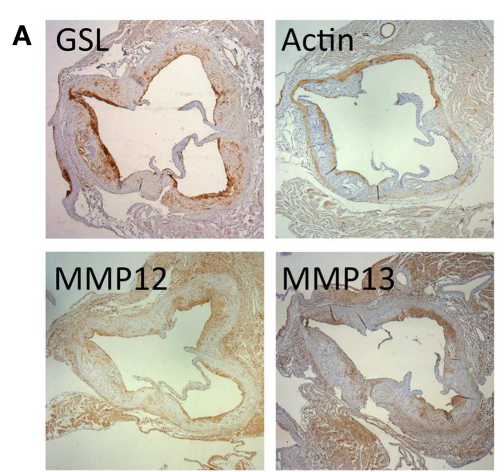

B GSL
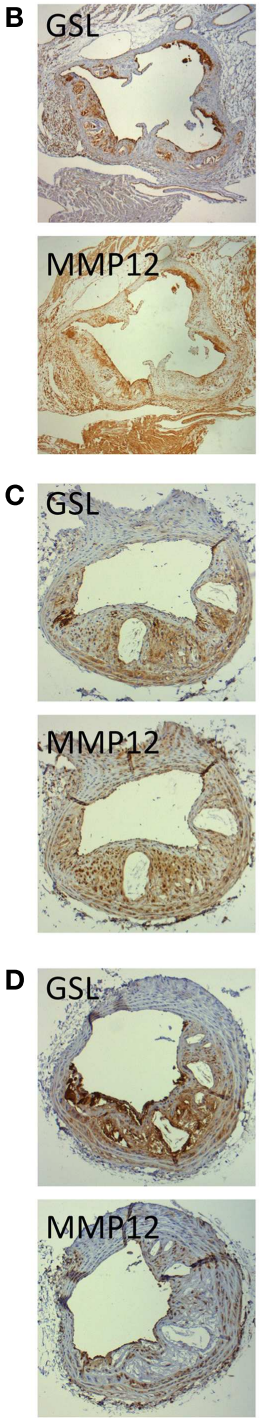
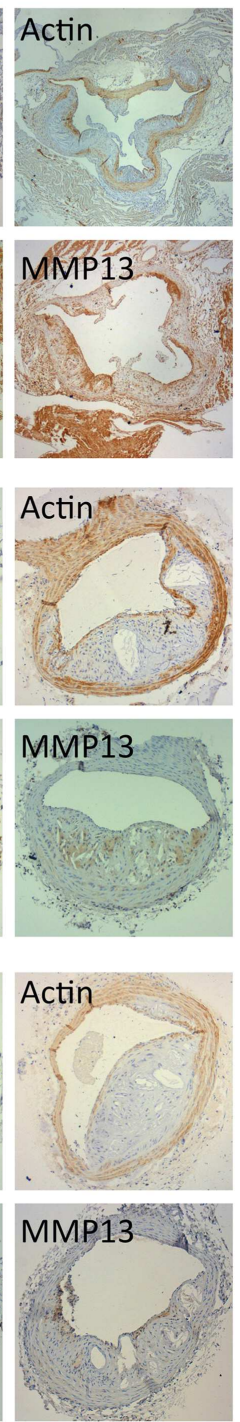
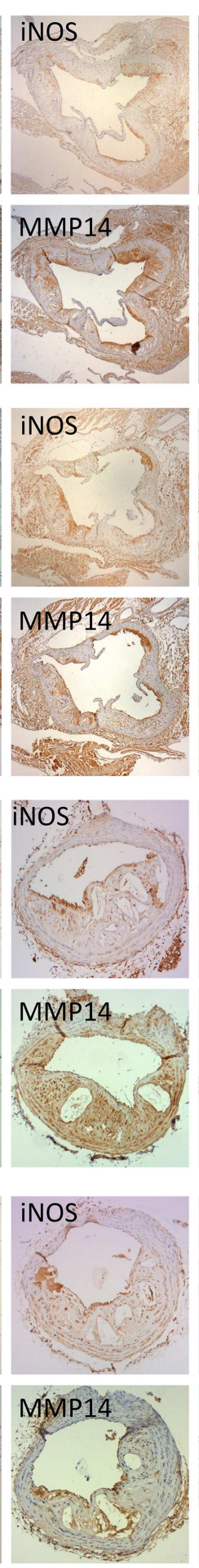
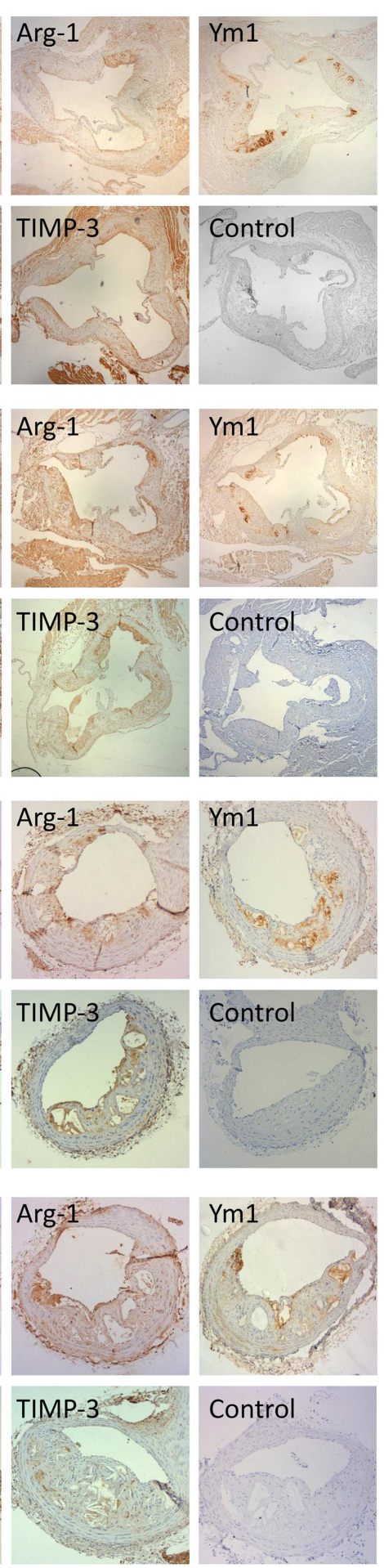

FIGURE 7 | Immunohistochemical staining for cell type, M1 and M2 markers and for MMPs and TIMPs. Near consecutive sections to the section stained with elastin/van Gieson (EVG) were subjected to immunohistochemistry for macrophages [Griffonia simplicifolia lectin II (GSL)], smooth muscle cells ( $\alpha$-smooth muscle actin; actin), iNOS, arg-1, Ym-1, MMP-12, MMP-13, MMP-14, and TIMP-3, using the antibodies detailed in
Table 2. Controls were performed with non-immune IgG or normal serum replacing the primary antibody. (A) Aortic sinus plaques from ApoE KO mice (Magnification: $\times 4$ ). (B) Aortic sinus plaques from ApoE/Rag1 DKO mice (Magnification: $\times 4$ ). (C) Brachiocephalic artery plaques from ApoE KO mice (Magnification: $\times 10$ ). (D) Brachiocephalic artery plaques from ApoE/Rag1 DKO mice (Magnification: $\times 10$ ). 


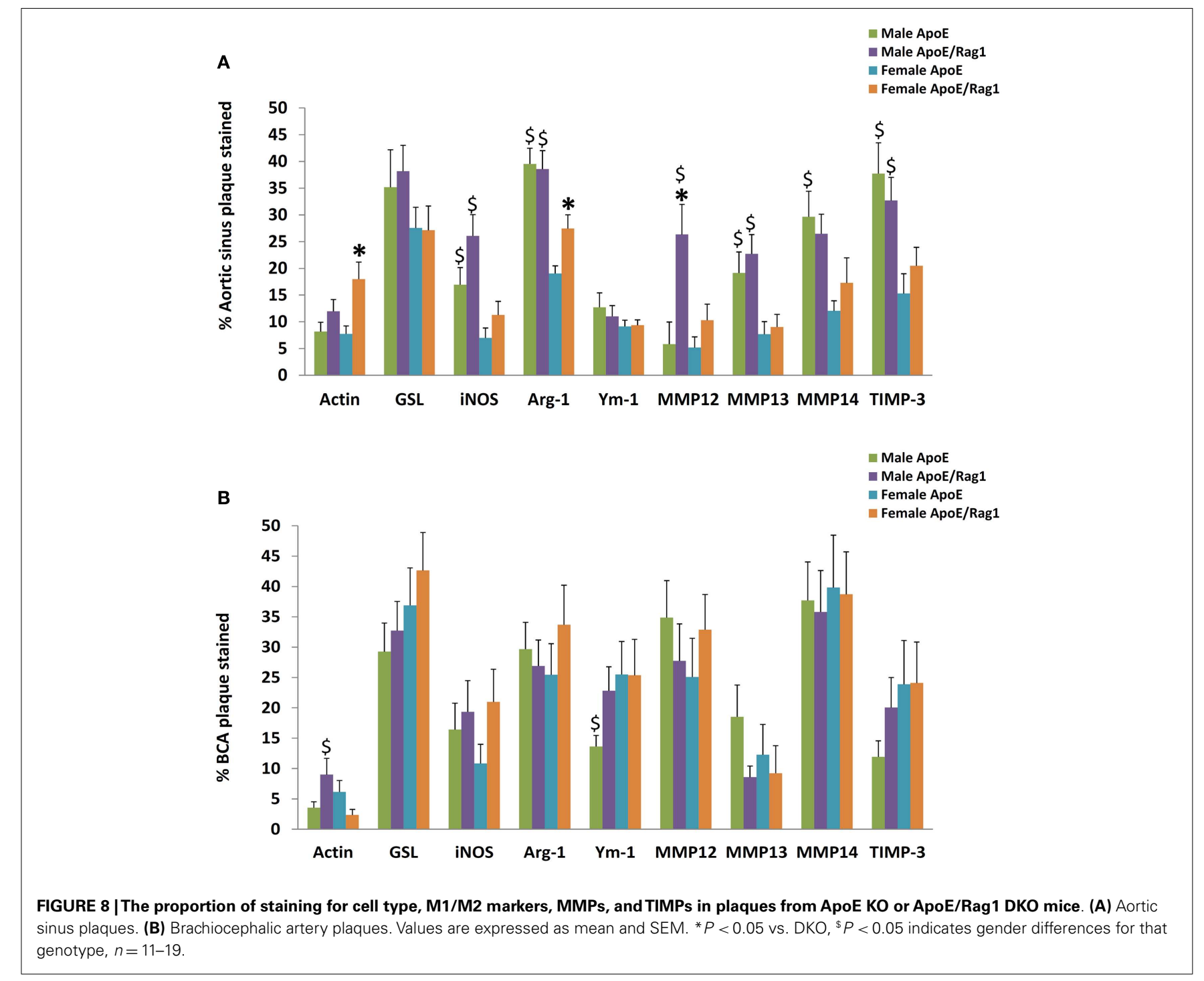

\section{DISCUSSION}

The clear conclusion from our experiments is that FCMs in subcutaneous granulomas and atherosclerotic plaques acquired markers of classical (M1) and alternative (M2) activation even in the absence of lymphocytes. This conclusion was valid in male and female mice, despite differences in the size and composition of plaques between the two genders. Furthermore, since nuclear localized NF- $\kappa$, phospho-STAT-1 and phospho-STAT6 were detected in granuloma FCMs, activators of the pathways leading to M1 and M2 polarization also existed in adequate quantities in the presence or absence of $\mathrm{T}$ or B lymphocytes. We also observed that expression of several MMPs and TIMPs occurred in granuloma and plaque FCMs in vivo independently of T and B lymphocytes.

Recent work demonstrated that foam cell formation did not, in itself, lead to M1 or M2 activation (28). By contrast, peritoneal FCM generated in vivo were resistant to M1 activation, owing to stimulation of the LXR pathway. Nevertheless, several studies showed that there are FCMs in mouse atherosclerotic plaques that express both M1 and M2 markers either in situ (12, 13) or after collagenase isolation (32). M1 and M2 markers were associated with distinct cell populations even though they had overlapping distributions in the intima of advanced mouse plaques (32). Our histological observations confirmed these findings but showed, in addition, that FCMs produced in the context of the foreign body reaction caused by a polyurethane sponge implantation also prominently expressed M1 and M2 markers. Granuloma FCMs mimicked the gene expression pattern of plaque FCMs and may therefore be useful as a more-easily isolated surrogate. Functionally, iNOS and arg-1 appear to compete for substrate. Indeed, in a previous study, we demonstrated this directly in rabbit FCMs where down-regulation of arg-1 compared to nonfoamy macrophages led to decreased urea and increased nitrate release (24).

In previous papers dealing with atherosclerosis, it has been acknowledged that Th1- and Th2-lymphocyte related cytokines can polarize macrophages toward M1 and M2 phenotypes, respectively (11-13). This suggests that lymphocytes and hence, 
by implication, adaptive immunity plays an essential role in macrophage polarization, albeit in concert with other factors (11). On the contrary, our new data show clearly that M1/M2 polarization of FCMs can take place efficiently in the absence of $\mathrm{T}$ and $\mathrm{B}$ cells. To do this, we recreated a previously-characterized cross (20) between the well-established ApoE KO mouse and the equally well-characterized Rag1 KO mouse. We obtained similar development of plaques in these mice as previously observed (20) and then went on to make novel observations of macrophage phenotypes in subcutaneous granulomas and plaques.

It is worth noting that the absolute copy numbers of the M1 and M2 marker mRNAs measured in granuloma FCMs were of the same order of magnitude as those in measured in classical and alternatively activated macrophages in vitro (compare Table 5 to Figure 1A). Despite the obvious limitations of comparing data across such different experimental conditions, it is hard to escape the conclusion that the FCMs produced in vivo express M1 and M2 marker genes to a substantial degree, irrespective of the presence of lymphocytes. Moreover, the canonical pathways of classical activation, NF- $\kappa$ B and STAT-1, and alternative activation, STAT- 6 , are also triggered in $\mathrm{T}$ and $\mathrm{B}$ cell deficient mice. One possible explanation is that TLR-4 mediated induction of so-called interferon response factors (IRFs, specifically IRF-3 and IRF-7) can lead to the secretion of IFN $\alpha$ and IFN $\beta$, thereby bypassing the requirement for IFN $\gamma$ (9). Plaques contain several potential activators of TLRs (33); and these could well be the sources of classical activation. In addition to TLR agonists, other stimulators of the NF- $\kappa$ B pathway, including TNF $\alpha$ and IL-1, that are known to occur in mouse atherosclerotic plaques (3) could also act as classical activators independently of IFN $\gamma$, as shown in many previous studies $(3,14)$. The presence of these alternative mediators therefore provides a rationale for $\mathrm{M} 1$ activation in $\mathrm{T}$ and $\mathrm{B}$ cell depleted mice, although additional experiments beyond the present scope would be needed to identify the specific mediators. M2 polarization can also occur in response to a variety of mediators, although activation of STAT- 6 appears to indicate the mediation of IL- 4 and/or IL-13 in our mice even in the absence of lymphocytes. An additional, non-exclusive explanation for our findings is that there are sources other than lymphocytes for the cytokines associated with M1 and M2 activation in mice. For example, natural killer cells were shown to be an active source of IFN $\gamma$ in Rag-1 KO mice (34) and could therefore account for the residual levels of IFN $\gamma$ we observed in the blood of ApoE/Rag-1 DKO mice (Table 3). Likewise, mast cells (35) and neutrophils (36) are plausible sources of IL-4 and IL-13 in lymphocyte-depleted mice.

MMPs have been strongly implicated in the progression of atherosclerosis, and more particularly in ECM degradation as well migration, proliferation and apoptosis of vascular cells $(5,37)$. The results in Figure 1B showing that MMP-2, MMP-9, MMP-13, MMP-14, and MMP-25 were up-regulated and TIMP-2 downregulated in mouse macrophages during classical activation are consistent with previously reviewed data for MMP-9 and MMP13 (38). However, IFN $\gamma$ had no effect on MMP or TIMP mRNA expression in mouse macrophages at the 18-h time point we used (Figures 1C,D), which was chosen to allow time for priming effects to be observed. Up-regulation of MMP-19 and down-regulation of MMP-14 were the only changes that we observed in response to IL-4 (Figure 1B). Furthermore, there was no difference in the expression level of any of the MMPs or TIMPs in FCMs isolated from sponge granulomas in ApoE KO and DKO mice. Despite this, there was a small increase in the proportion of cells able to degrade gelatin in DKO mice, which might be explained by the trend toward increases in MMP-2 and MMP-9 mRNA expressions. Further experiments would be needed to verify this. Recent work has placed increased emphasis on macrophage proliferation in mouse atherosclerosis (39). Specifically, it has been suggested that proliferation, rather than recruitment, is the major factor leading to accumulation of FCMs into atherosclerotic plaques of ApoE null mice at early time points (40). We found a relative decrease in FCMs from female DKO mice, but this did not appear to be associated with differences in M1/M2 polarization or MMP expression. Turning to our immunohistochemical studies of atherosclerotic plaques, few changes were noted in the extent of MMP-12, -13, -14 , or TIMP-3 staining. Only MMP-12 staining appeared to be increased in male DKO mice in the AS but not BCA. Since, we found no effect of classical or alternative activation on MMP-12 expression in vitro, this isolated observation might be explained by another mediator such as GM-CSF, which has been shown to up-regulate MMP-12 in several, previously reviewed studies (38). However, the plasma cytokine levels (Table 3 ) provide no corroboration for this contention.

During the course of our studies, we noted significant differences in cytokine and lipid levels, plaque sizes, and content of SMC between male and female mice that obliged us to consider these data separately. We found smaller AS plaques in male than female ApoE KO mice, similar to what has been previously noted and attributed to the effects of estrogens (19) and prostaglandins (41). On the other hand, we found that males develop larger lesions in the BCA, confirming what we previously published in thesis form (29) and consonant with findings in the aorta at longer time points (18). This is most likely related, at least in part, to the higher total cholesterol and VLDL + LDL levels, we observed in male mice (Table 4). The important fact to stress, however, is that acquisition of M1 and M2 markers and expression of MMPs and TIMP was independent of $\mathrm{T}$ and $\mathrm{B}$ lymphocytes, irrespective of the gender of mice we analyzed.

Human atherosclerotic plaques also have prominent populations of FCMs that show M1 markers $(42,43)$ and have been known for many years to have nuclear localized NF- $\mathrm{B}$ (44). Consistent with our present results, work on cells isolated from human atherosclerotic plaques, placed emphasis on innate immune mechanisms, by showing that TLR-2 activation plays an important role in M1 polarization and MMP secretion (45). There are also foci of FCMs in the intima that express M2 markers, which are distinct from FCMs carrying M1 markers (11). Non-foamy macrophages carrying M2 markers are even more prevalent in the adventitia (43). Hence, the distribution of cells carrying M2 markers in human plaques appears to be more restricted than in the mouse plaques in our study (Figures 7A-D) and in those previously published $(12,13)$.

With respect to MMPs and TIMPs, comparison of our in vitro results with published data from human macrophages isolated and incubated under very similar conditions $(38,42,46)$ demonstrates many differences. For example, MMP-1 is absent but MMP-13 
is abundant in mouse macrophages, whereas MMP-13 is absent and MMP-1 is abundant in human macrophages $(42,47)$, consistent with the limited distribution of MMP-13 in human tissues (48). Furthermore, MMP-12 is apparently much more abundant in mouse macrophages (Figure 1B) than human macrophages (42). Conversely, mRNAs for MMP-2, MMP-3, MMP-7, MMP-9, MMP-10, MMP-11, MMP-17, TIMP-1, and TIMP-3 appear much less abundant in mouse macrophages (Figure 1B) than human macrophages (42). Only MMP-8, MMP-14, MMP-19, MMP-25, and TIMP-2 show similar (within 10-fold) abundance in both species at the mRNA level. Responses of MMPs and TIMPs to classical and alternative also present stark contrasts between mice and men, under the conditions of our experiments. For example, expression of MMP-1, MMP-3, MMP-7, MMP-10, MMP12 , and TIMP-1 was increased by classical activation of human macrophages, whereas MMP-9 was constitutive (42), in contrast to what we observed here (Figure 1B). Furthermore, IFN $\gamma$ increased MMP-1, MMP-10, MMP-12, and MMP-14 expression and decreased TIMP-3 expression in human macrophages (42), none of which we observed in mouse macrophages at the same time point (Figure 1C). Finally, IL-4 treatment increased MMP11, MMP-12, and TIMP-3 expression in human macrophages (42) but MMP-19 expression in mice (Figure 1B). Similar disparity has been previously noted with respect to the expression levels of M1 and M2 markers in human and mouse macrophages (15). Moreover, the overall transcriptomic response to several in vivo models of inflammation appears highly divergent in mice and men (49). These limitations therefore caution against over-extrapolating our present results from a mouse model to human atherosclerosis.

In conclusion, our results definitively counter the hypothesis that lymphocytes are necessary for M1 or M2 polarization in mouse atherosclerosis, although more work will be needed to define the mediators responsible. Lymphocytes are also not needed for MMP and TIMP expression in FCMs in vivo. However, our studies do not rule out a modulatory role for $\mathrm{T}$ or $\mathrm{B}$ lymphocytes on either macrophage polarization or MMP production. It is conceivable that deletion of different lymphocyte populations has opposing effects of macrophage and foam cell activation, leading to a neutral effect overall. Subsequent studies using more selective interventions will be needed to investigate the role of specific lymphocyte subsets in mice.

\section{ACKNOWLEDGMENTS}

This work was supported by funding from by the British Heart Foundation. The authors would like to thank Mrs. Kristina Baker for her help with some tissue harvests and KWS BioTest Ltd. for measuring the cytokine levels.

\section{REFERENCES}

1. Smith JD, Trogan E, Ginsberg M, Grigaux C, Tian J, Miyata M. Decreased atherosclerosis in mice deficient in both macrophage colony-stimulating factor (op) and apolipoprotein E. Proc Natl Acad Sci U S A (1995) 92:8264-8. doi:10.1073/pnas.92.18.8264

2. Paulson KE, Zhu SN, Chen M, Nurmohamed S, Jongstra-Bilen J, Cybulsky MI. Resident intimal dendritic cells accumulate lipid and contribute to the initiation of atherosclerosis. Circ Res (2010) 106:383-90. doi:10.1161/CIRCRESAHA.109. 210781

3. Tedgui A, Mallat Z. Cytokines in atherosclerosis: pathogenic and regulatory pathways. Physiol Rev (2006) 86:515-81. doi:10.1152/physrev.00024.2005
4. Bennett M, Yu H, Clarke M. Signalling from dead cells drives inflammation and vessel remodelling. Vascul Pharmacol (2012) 56:187-92. doi:10.1016/j.vph. 2012.01.006

5. Libby P. Collagenases and cracks in the plaque. J Clin Invest (2013) 123:3201-3. doi:10.1172/JCI67526

6. Adams DO, Hamilton TA. The cell biology of macrophage activation. Annu Rev Immunol (1984) 2:283-318. doi:10.1146/annurev.iy.02.040184.001435

7. Mosser DM, Edwards JP. Exploring the full spectrum of macrophage activation. Nat Rev Immunol (2008) 8:958-69. doi:10.1038/nri2448

8. Martinez FO, Gordon S, Locati M, Mantovani A. Transcriptional profiling of the human monocyte-to-macrophage differentiation and polarization: new molecules and patterns of gene expression. J Immunol (2006) 177:7303-11. doi:10.4049/jimmunol.177.10.7303

9. Hu X, Chakravarty SD, Ivashkiv LB. Regulation of interferon and toll-like receptor signaling during macrophage activation by opposing feedforward and feedback inhibition mechanisms. Immunol Rev (2008) 226:41-56. doi:10.1111/j. 1600-065X.2008.00707.x

10. Platanias LC. Mechanisms of type-I- and type-II-interferon-mediated signalling. Nat Rev Immunol (2005) 5:375-86. doi:10.1038/nri1604

11. Bouhlel MA, Derudas B, Rigamonti E, Dievart R, Brozek J, Haulon S, et al. PPARgamma activation primes human monocytes into alternative M2 macrophages with anti-inflammatory properties. Cell Metab (2007) 6:137-43. doi:10.1016/j.cmet.2007.06.010

12. Kadl A, Meher AK, Sharma PR, Lee MY, Doran AC, Johnstone SR, et al. Identification of a novel macrophage phenotype that develops in response to atherogenic phospholipids via Nrf2. Circ Res (2010) 107:737-46. doi:10.1161/ CIRCRESAHA.109.215715

13. Cardilo-Reis L, Gruber S, Schreier SM, Drechsler M, Papac-Milicevic N, Weber $\mathrm{C}$, et al. Interleukin-13 protects from atherosclerosis and modulates plaque composition by skewing the macrophage phenotype. EMBO Mol Med (2012) 4:1072-86. doi:10.1002/emmm.201201374

14. Mantovani A, Sica A, Sozzani S, Allavena P, Vecchi A, Locati M. The chemokine system in diverse forms of macrophage activation and polarization. Trends Immunol (2004) 25:677-86. doi:10.1016/j.it.2004.09.015

15. Martinez FO, Helming L, Gordon S. Alternative activation of macrophages: an immunologic functional perspective. Annu Rev Immunol (2009) 27:451-83. doi:10.1146/annurev.immunol.021908.132532

16. Mills CD, Kincaid K, Alt JM, Heilman MJ, Hill AM. M-1/M-2 macrophages and the Th1/Th2 paradigm. J Immunol (2000) 164:6166-73. doi:10.4049/jimmunol. 164.12.6166

17. Libby P, Lichtman AH, Hansson GK. Immune effector mechanisms implicated in atherosclerosis: from mice to humans. Immunity (2013) 38:1092-104. doi:10.1016/j.immuni.2013.06.009

18. Tangirala RK, Rubin EM, Palinski W. Quantitation of atherosclerosis in murine models: correlation between lesions in the aortic origin and in the entire aorta, and differences in the extent of lesions between sexes in LDL receptor-deficient and apolipoprotein E-deficient mice. J Lipid Res (1995) 36: 2320-8.

19. Caligiuri G, Nicoletti A, Zhou X, Tornberg I, Hansson GK. Effects of sex and age on atherosclerosis and autoimmunity in apoE-deficient mice. Atherosclerosis (1999) 145:301-8. doi:10.1016/S0021-9150(99)00081-7

20. Daugherty A, Pure E, Delfel-Butteiger D, Chen S, Leferovich J, Roselaar SE, et al. The effects of total lymphocyte deficiency on the extent of atherosclerosis in apolipoprotein $\mathrm{E}^{-/-}$mice. J Clin Invest (1997) 100:1575-80. doi:10.1172/JCI119681

21. Di Gregoli K, Jenkins N, Salter R, White S, Newby AC, Johnson JL. MicroRNA-24 regulates macrophage behavior and retards atherosclerosis. Arterioscler Thromb Vasc Biol (2014) 34:1990-2000. doi:10.1161/ATVBAHA.114.304088

22. Chase A, Bond M, Crook MF, Newby AC. Role of nuclear factor-kB activation in metalloproteinase-1, -3 and -9 secretion by human macrophages in vitro and rabbit foam cells produced in vivo. Arterioscler Thromb Vasc Biol (2002) 22:765-71. doi:10.1161/01.ATV.0000015078.09208.92

23. Johnson JL, Devel L, Czarny B, George SJ, Jackson CL, Rogakos V, et al. A selective matrix metalloproteinase-12 inhibitor retards atherosclerotic plaque development in apolipoprotein E-knockout aice. Arterioscler Thromb Vasc Biol (2011) 31:528-35. doi:10.1161/ATVBAHA.110.219147

24. Thomas AC, Sala-Newby GB, Ismail Y, Johnson JL, Pasterkamp G, Newby AC. Genomics of foam cells and nonfoamy macrophages from rabbits identifies arginase-I as a differential regulator of nitric oxide production. 
Arterioscler Thromb Vasc Biol (2007) 27:571-7. doi:10.1161/01.ATV.0000256470. 23842.94

25. Hadler-Olsen E, Kanapathippillai P, Berg E, Svineng G, Winberg JO, UhlinHansen L. Gelatin in situ zymography on fixed, paraffin-embedded tissue: zinc and ethanol fixation preserve enzyme activity. J Histochem Cytochem (2010) 58:29-39. doi:10.1369/jhc.2009.954354

26. Paigen B, Ishida BY, Verstuyft J, Winters RB, Albee D. Atherosclerosis susceptibility differences among progenitors of recombinant inbred strains of mice. Arterioscler Thromb Vasc Biol (1990) 10:316-23. doi:10.1161/01.ATV. 10.2.316

27. Newby AC, George SJ, Ismail Y, Johnson JL, Sala-Newby GB, Thomas AC. Vulnerable atherosclerotic plaque metalloproteinases and foam cell phenotypes. Thromb Haemost (2009) 101:1006-11. doi:10.1160/TH08-07-0469

28. Spann NJ, Garmire LX, Mcdonald JG, Myers DS, Milne SB, Shibata N, et al. Regulated accumulation of desmosterol integrates macrophage lipid metabolism and inflammatory responses. Cell (2012) 151:138-52. doi:10.1016/j.cell.2012.06.054

29. Johnson JL. The Role of Matrix Metalloproteinases in an Animal Model of Atherosclerotic Plaque Rupture. PhD. Bristol: University of Bristol (2005).

30. Johnson JL, Carson K, Williams HM, Karanam S, Newby AC, Angelini GD, et al. Plaque rupture after short periods of fat-feeding in the apolipoprotein $\mathrm{E}$ knockout mouse: model characterisation, and effects of pravastatin treatment. Circulation (2005) 111:1422-30. doi:10.1161/01.CIR.0000158435. 98035.8D

31. Rong JX, Shapiro M, Trogan E, Fisher EA. Transdifferentiation of mouse aortic smooth muscle cells to a macrophage-like state after cholesterol loading. Proc Natl Acad Sci U S A (2003) 100:13531-6. doi:10.1073/pnas.1735526100

32. Koltsova EK, Hedrick CC, Ley K. Myeloid cells in atherosclerosis: a delicate balance of anti-inflammatory and proinflammatory mechanisms. Curr Opin Lipidol (2013) 24:371-80. doi:10.1097/MOL.0b013e328363d298

33. Erridge C. The roles of toll-like receptors in atherosclerosis. J Innate Immun (2009) 1:340-9. doi:10.1159/000191413

34. Thale C, Kiderlen AF. Sources of interferon-gamma (IFN-gamma) in early immune response to listeria monocytogenes. Immunobiology (2005) 210:673-83. doi:10.1016/j.imbio.2005.07.003

35. Bradding P, Feather IH, Howarth PH, Mueller R, Roberts JA, Britten K, et al. Interleukin 4 is localized to and released by human mast cells. J Exp Med (1992) 176:1381-6. doi:10.1084/jem.176.5.1381

36. Brandt E, Woerly G, Younes AB, Loiseau S, Capron M. IL-4 production by human polymorphonuclear neutrophils. J Leukoc Biol (2000) 68:125-30.

37. Newby AC. Matrix metalloproteinase inhibition therapy for vascular diseases. Vascl Pharmacol (2012) 56:232-44. doi:10.1016/j.vph.2012.01.007

38. Newby AC. Metalloproteinase expression in monocytes and macrophages and its relationship to atherosclerotic plaque instability. Arterioscler Thromb Vasc Biol (2008) 28:2108-14. doi:10.1161/ATVBAHA.108.173898

39. Andrés V, Pello OM, Silvestre-Roig C. Macrophage proliferation and apoptosis in atherosclerosis. Current Opin Lipidol (2012) 23:429-38. doi:10.1097/MOL. 0b013e328357a379

40. Robbins CS, Hilgendorf I, Weber GF, Theurl I, Iwamoto Y, Figueiredo JL, et al. Local proliferation dominates lesional macrophage accumulation in atherosclerosis. Nat Med (2013) 19:1166-72. doi:10.1038/nm.3258

41. Smith DD, Tan X, Tawfik O, Milne G, Stechschulte DJ, Dileepan KN. Increased aortic atherosclerotic plaque development in female apolipoprotein E-null mice is associated with elevated thromboxane $\mathrm{A} 2$ and decreased prostacyclin production. J Physiol Pharmacol (2010) 61:309-16.

42. Huang WC, Sala-Newby GB, Susana A, Johnson JL, Newby AC. Classical macrophage activation up-regulates several matrix metalloproteinases through mitogen activated protein kinases and nuclear factor-kappaB. PLoS One (2012) 7:e42507. doi:10.1371/journal.pone.0042507

43. Stoger JL, Gijbels MJ, Van Der Velden S, Manca M, Van Der Loos CM, Biessen EA, et al. Distribution of macrophage polarization markers in human atherosclerosis. Atherosclerosis (2012) 225:461-8. doi:10.1016/j.atherosclerosis.2012.09.013

44. Brand K, Page S, Rogler G, Bartsch A, Brandl R, Knuechel R, et al. Activated transcription factor nuclear factor-kappa $\mathrm{B}$ is present in the atherosclerotic lesion. J Clin Invest (1996) 97:1715-22. doi:10.1172/JCI118598

45. Monaco C, Gregan SM, Navin TJ, Foxwell BM, Davies AH, Feldmann M. Tolllike receptor-2 mediates inflammation and matrix degradation in human atherosclerosis. Circulation (2009) 120:2462-9. doi:10.1161/CIRCULATIONAHA. 109.851881

46. Reel B, Sala-Newby GB, Huang W-C, Newby AC. Diverse patterns of cyclooxygenase-independent metalloproteinase gene regulation in human monocytes. Br J Pharmacol (2011) 163:1679-90. doi:10.1111/j.1476-5381.2011. 01298.x

47. Bar-Or A, Nuttall RK, Duddy M, Alter A, Kim HJ, Ifergan I, et al. Analyses of all matrix metalloproteinase members in leukocytes emphasize monocytes as major inflammatory mediators in multiple sclerosis. Brain (2003) 126:2738-49. doi:10.1093/brain/awg285

48. Vincenti MP, Brinckerhoff CE. Transcriptional regulation of collagenase (MMP1, MMP-13) genes in arthritis: integration of complex signaling pathways for the recruitment of gene-specific transcription factors. Arthritis Res (2002) 4:157-64. doi:10.1186/ar401

49. Seok J, Warren HS, Cuenca AG, Mindrinos MN, Baker HV, Xu WH, et al. Genomic responses in mouse models poorly mimic human inflammatory diseases. Proc Natl Acad Sci U S A (2013) 110:3507-12. doi:10.1073/pnas. 1222878110

Conflict of Interest Statement: The authors declare that the research was conducted in the absence of any commercial or financial relationships that could be construed as a potential conflict of interest.

Received: 29 July 2014; accepted: 10 October 2014; published online: 28 October 2014. Citation: Hayes EM, Tsaousi A, Di Gregoli K, Jenkinson SR, Bond AR, Johnson JL, Bevan L, Thomas AC and Newby AC (2014) Classical and alternative activation and metalloproteinase expression occurs in foam cell macrophages in male and female ApoE null mice in the absence of $T$ and B lymphocytes. Front. Immunol. 5:537. doi: 10.3389/fimmu.2014.00537

This article was submitted to Inflammation, a section of the journal Frontiers in Immunology.

Copyright @ 2014 Hayes, Tsaousi, Di Gregoli, Jenkinson, Bond, Johnson, Bevan, Thomas and Newby. This is an open-access article distributed under the terms of the Creative Commons Attribution License (CC BY). The use, distribution or reproduction in other forums is permitted, provided the original author(s) or licensor are credited and that the original publication in this journal is cited, in accordance with accepted academic practice. No use, distribution or reproduction is permitted which does not comply with these terms. 